
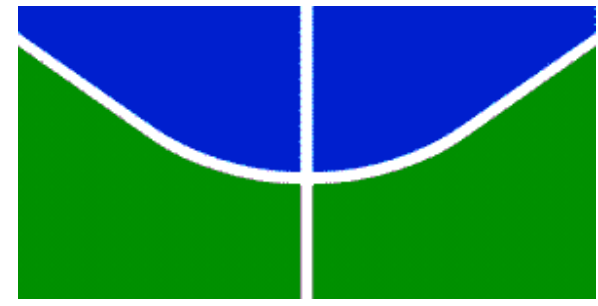

Universidade de Brasília

Instituto de Psicologia

Departamento de Processos Psicológicos Básicos

Pós-Graduação em Ciências do Comportamento

\title{
Efeitos do controle temporal sobre a escolha entre impulsividade e autocontrole
}

\author{
Lesley Diana de Sousa
}

Orientador: Josele Abreu-Rodrigues 

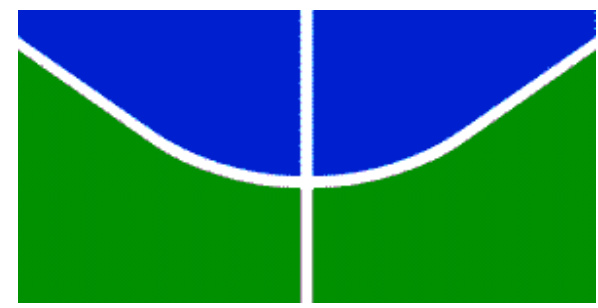

Universidade de Brasília

Instituto de Psicologia

Departamento de Processos Psicológicos Básicos

Pós-Graduação em Ciências do Comportamento

\title{
Efeitos do controle temporal sobre a escolha entre impulsividade e autocontrole
}

\author{
Lesley Diana de Sousa
}

Orientadora: Josele Abreu-Rodrigues

\begin{abstract}
Dissertação apresentada ao Programa de Pós-Graduação em Ciências do Comportamento do Departamento de Processos Psicológicos Básicos, Instituto de Psicologia, Universidade de Brasília, como parte dos requisitos para obtenção do grau de Mestre em Ciências do Comportamento (Área de Concentração: Análise do Comportamento).
\end{abstract}


Esta dissertação foi desenvolvida no Laboratório de Análise Experimental do Comportamento (Departamento de Processos Psicológicos Básicos, Instituto de Psicologia, Universidade de Brasília) com o auxílio de uma bolsa de mestrado concedida pela CAPES.

\section{Comissão Examinadora}

Dra. Josele Abreu-Rodrigues (Presidente)

Universidade de Brasília

Dra. Júnnia Maria Moreira (Membro Externo)

Universidade Federal do Vale do São Francisco

Dr. Carlos Renato Xavier Cançado (Membro Interno)

Universidade de Brasília

Dr. Jorge Mendes de Oliveira Castro Neto (Membro Suplente)

Universidade de Brasília 


\section{Agradecimentos}

Como é maravilhosa a parte da escrita dos agradecimentos! O momento de lembrarse das pessoas que contribuíram de maneira direta ou indireta para a realização desse trabalho. Poderia escrever uma lista de nomes gigantesca, pois, mais do que o conhecimento adquirido durante esses dois anos, levo uma profunda gratidão por cada pessoa que dedicou um pouco do seu tempo para me oferecer uma palavra, um abraço ou um sorriso. Cada gesto foi extremamente importante. Sem a ajuda de tantas pessoas queridas, não teria sido possível a realização desse trabalho.

Agradeço primeiramente à minha mãe Lauriana Zacarias, minha melhor amiga e companheira. Sem dúvida, a pessoa mais importante na minha vida. Sou imensamente feliz e honrada por ser sua filha. Nunca conseguirei agradecer o suficiente todo o apoio, suporte, carinho e amor que você me oferece. Ao meu pai Moacir Gonçalves também por todo apoio, carinho, amor e incentivo durante esse período. Além disso, por ser uma pessoa de quem eu me orgulho e na qual eu me espelho. Espero um dia conseguir ser um pouco da pessoa de bem, honesta e humilde que você é.

A Jô, por todo o carinho, cuidado, paciência, preocupação, profissionalismo, disposição, incentivo e dedicação. É encantador ver a sua paixão pela pesquisa básica. Sem dúvida umas das profissionais mais competentes que tive a honra de conhecer e trabalhar. Aprendi muito com você Jô, não somente no âmbito profissional, mas também no âmbito pessoal. São aprendizados que levarei por toda a vida.

Ao meu companheiro Jhonathan, por ter sido tão maravilhoso durante esse período, por ter apoiado as minhas decisões, acreditado em mim, se esforçado para garantir o meu bem estar e por todo o zelo com a nossa relação. Nem mesmo nos meus melhores pensamentos eu poderia “criar" um companheiro que me fizesse mais feliz do que você. 
Ao professor e querido amigo Fábio Baia, por quem eu tenho tamanha admiração. Obrigada por ter me apresentado à Análise do Comportamento de um modo tão apaixonante. Se eu não tivesse lhe conhecido, jamais teria vivido tantas experiências incríveis como as que vivi durante o mestrado, tanto no contexto acadêmico, quanto no contexto pessoal. Obrigada por ter me incentivado e me acompanhado antes e durante esse período. Sou muito feliz em saber que posso contar com você.

Aos professores Carlos Cançado e Raquel Aló, por compartilhar tanto conhecimento durante as disciplinas e durante a convivência diária no laboratório. Poder aprender com vocês foi muito enriquecedor para a minha formação.

Ao meu amigo Hedian, que me acolheu em sua casa quando cheguei a Brasília. Obrigada por dividir comigo o seu cantinho. Sem dúvida, ter a companhia de um amigo tão querido e amável tornaram as coisas bem mais leves.

Às minhas queridas anjinhas Karen e Flávia, a amizade de vocês é um bem muito precioso. Fico extremamente feliz em ver que hoje, ao final desses dois anos, parte do que eu sou é fruto da minha interação com vocês. Sinto muito orgulho disso.

Aos meus amigos Paulo e Raiene, que mesmo longe, sempre estiveram por perto, me acompanhando e oferecendo todo o suporte, carinho, cuidado e amor.

Aos meus amigos Ítalo e Amanda, pela companhia diária, pelo apoio, pelos momentos de descontração, por todo o carinho, companheirismo e cuidado.

Aos membros da banca por terem aceitado o convite e pelas considerações.

Aos funcionários do laboratório, Hugo, Ademar, Carina, Salete, Enilvan e Suelen, por garantirem o bom funcionamento do laboratório graças ao excelente profissionalismo de vocês. 


\section{Índice}

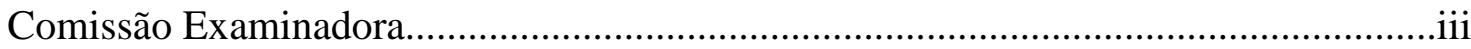

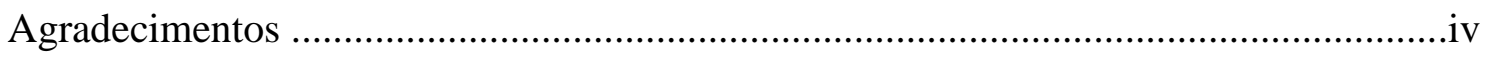

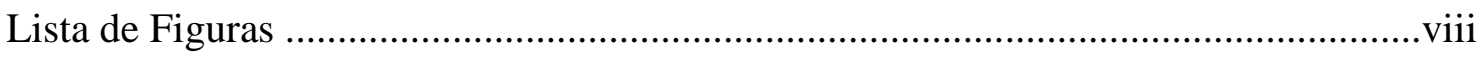

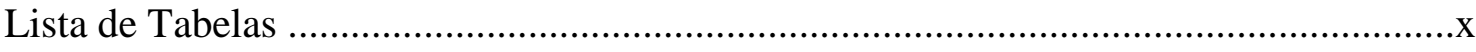

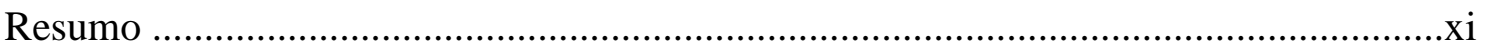

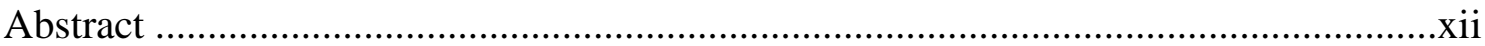

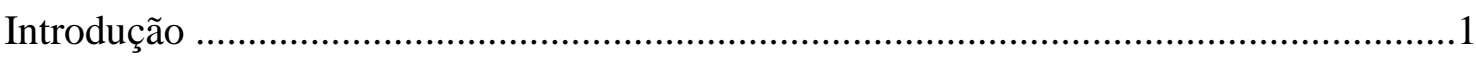

Variáveis que afetam a escolha por autocontrole ..............................................5

Duração do atraso ......................................................................6

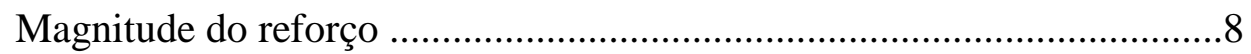

Probabilidade do reforço ...............................................................10

Atividades durante o atraso ............................................................. 10

Visualização do reforço ................................................................. 11

História experimental ................................................................. 12

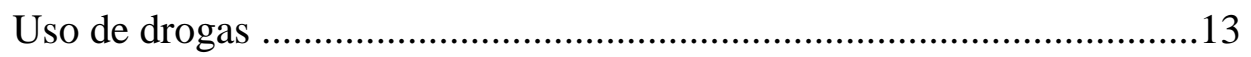

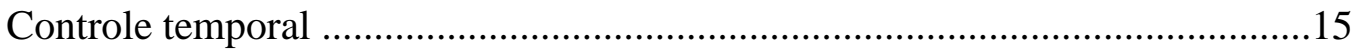

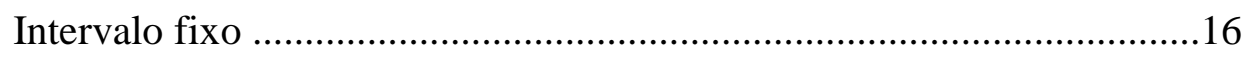

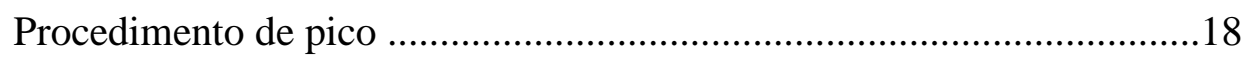

Reforçamento diferencial de taxas baixas ..........................................20

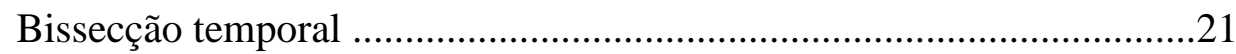

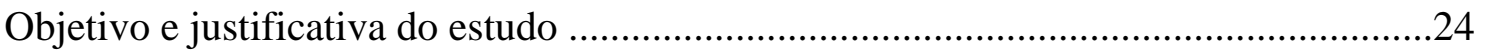

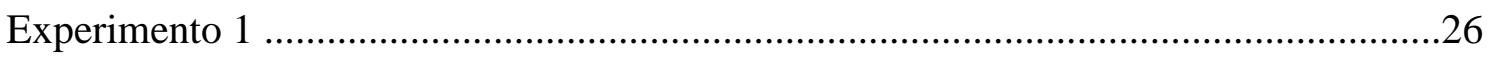

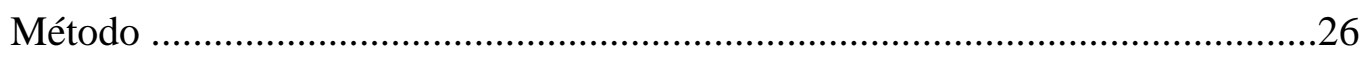

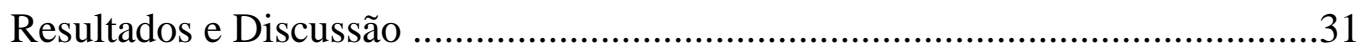




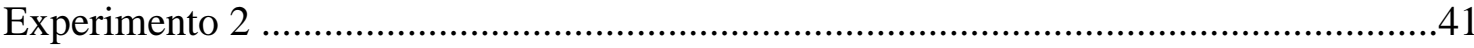

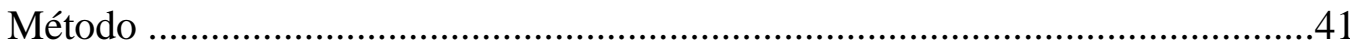

Resultados e Discussão ............................................................................44

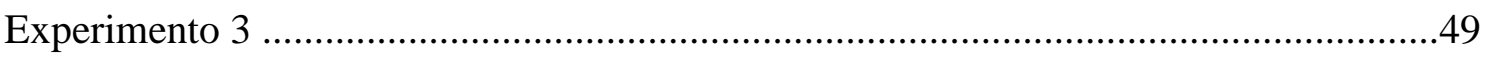

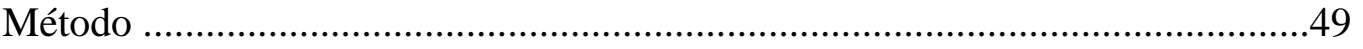

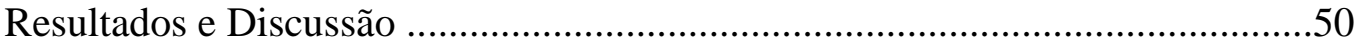

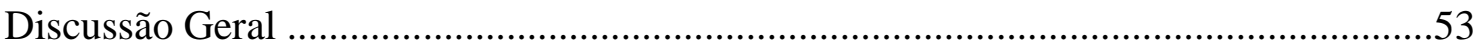

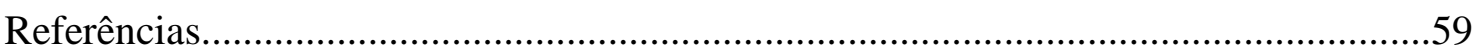




\section{Lista de Figuras}

Figura 1. Escolha relativa de $A C$ nas seis últimas sessões da fase LB imediatamente anterior ao treino com os esquemas FR, DRL e FI, para cada sujeito no Experimento 1. Os números1, 2 e 3 indicam a ordem de exposição aos esquemas. .32

Figura 2. Escolha relativa de AC em todas as sessões da fase TR+TT como uma proporção das escolhas relativas de AC na fase LB imediatamente anterior, para cada sujeito no Experimento 1. Os números 1, 2 e 3 indicam a ordem de exposição aos esquemas .38

Figura 3. Diferença entre a proporção de escolhas relativas de AC após a exposição aos esquemas FR e DRL, FR e FI, e DRL e FI, em todas as sessões da fase TR+TT, para cada sujeito no Experimento (a escala do eixo Y difere entre sujeitos) .40

Figura 4. Escolha relativa de $\mathrm{AC}$ nas seis últimas sessões da fase $\mathrm{LB}$, para cada sujeito no Experimento 2

Figura 5. Porcentagem de acertos para os modelos 'curto' e 'longo' nas cinco últimas sessões das fases TRBI e TRBI+TTBI, para cada sujeito no Experimento 2. Círculos vazios representam o modelo ‘curto' e círculos cheios representam o modelo ‘longo.......45

Figura 6. Proporção de escolhas na alternativa 'longo' em função da duração dos modelos apresentados nas cinco últimas sessões da fase TRBI+TTBI. Setas indicam o valor do PIS para cada sujeito no Experimento 2

Figura 7. Escolha relativa de AC nas 10 sessões da fase TT como uma proporção da escolha relativa de $\mathrm{AC}$ na fase $\mathrm{LB}$, para cada sujeito no Experimento 2. 48

Figura 8. Escolha relativa de AC na seis últimas sessões da fase LB, para cada sujeito no Experimento 3. .50 
Figura 9. Porcentagem de acertos para os modelos 'curto' e 'longo' nas últimas sessões da fase TRBI para cada sujeito no Experimento 3. Círculos vazios representam o modelo ‘curto’ e círculos cheios representam o modelo ‘longo........................................................

Figura 10. Escolha relativa de AC nas 10 sessões da fase TRBI+TT como uma proporção da escolha relativa de $\mathrm{AC}$ na fase $\mathrm{LB}$, para cada sujeito no Experimento 3. 52 


\section{Lista de Tabelas}

Tabela 1. Valor (V) do esquema, média (M) do IRI e da taxa de respostas da taxa de respostas (TxR), e desvio padrão (DP) nas quatro últimas sessões da fase TR e em todas as sessões da fase TR+TT, para cada sujeito no Experimento 1 .34

Tabela 2. Pausa pós-reforço média durante o esquema FI nas quatro últimas sessões da fase TRFI e em todas as sessões da fase TRFI+TT, para cada sujeito no Experimento

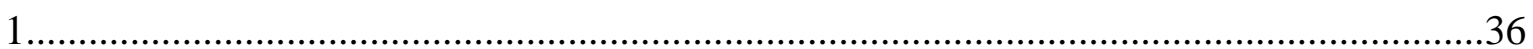




\section{Resumo}

Os efeitos do controle temporal sobre as escolhas entre impulsividade (IP) e autocontrole (AC) foram estudados por meio de um delineamento ABA. Na linha de base dos experimentos 1, 2 e 3, ratos foram expostos a uma tarefa de escolha entre IP e AC. No Experimento 1, a segunda fase correspondeu ao treino com três esquemas de reforçamento (FR, DRL e FI), e a terceira fase, ao retorno à tarefa de escolha. Foi observado um aumento nas escolhas de AC após o treino com o esquema FR, para a maioria dos sujeitos, mas não após o treino com os esquemas DRL e FI. Nos experimentos 2 e 3, após a linha de base, os sujeitos foram expostos ao procedimento de bissecção temporal. No Experimento 2, o treino e o teste de bissecção foram realizados antes do retorno à tarefa de escolha. No Experimento 3, o treino de bissecção e a tarefa de escolha ocorreram na mesma sessão. Em ambos os experimentos, houve aumento na escolha de AC, mas apenas para metade dos sujeitos. Em conjunto, os resultados do presente estudo sugerem que: (1) a emissão de respostas durante o tempo até o reforço pode diminuir as propriedades aversivas desse tempo e, consequentemente, favorecer escolhas autocontroladas; e (2) discriminação temporal parece não ser uma condição suficiente para a ocorrência de autocontrole.

Palavras-chave: autocontrole, impulsividade, escolha, controle temporal, ratos. 


\begin{abstract}
The effects of temporal control upon choice between impulsivity (IP) and selfcontrol (SC) were investigated with an ABA design. In baseline of experiments 1, 2 and 3, rats were exposed to a choice between IP and SC. In Experiment 1, during the second phase, one of three schedules of reinforcement (FR, DRL and FI) was in effect, and during the third phase, the choice task was reinstated. SC choices increased after training with the FR schedule, for most subjects, but not after training with the DRL and FI schedules. In experiments 2 and 3, after baseline, rats were exposed to a temporal bisection procedure. In Experiment 2, the bisection training and test were implemented before returning to the choice task. In Experiment 3, the bisection training and the choice task occurred within the same session. In both experiments, there was an increase in SC choices, but only for half of the subjects. Taken together, the results of the present study suggest that: (1) the emission of responses during the time until the next reinforcer may decrease the aversive properties of that time, and hence, favor self-controlled choices; and (2) temporal discrimination may not be sufficient for the occurrence of self-control.
\end{abstract}

Keywords: self-control, impulsivity, choice, temporal control, rats. 
Autocontrole, para o senso comum, está relacionado a causas internas do comportamento como, por exemplo, força de vontade ou características de personalidade. Também na Psicologia, o termo autocontrole é comumente utilizado para indicar um traço de personalidade, uma característica inata ou forças interiores. No entanto, um mesmo indivíduo pode, em diversos momentos da vida e/ou em variados contextos, apresentar diferentes níveis de autocontrole (Hanna \& Todorov, 2002). Explicações do comportamento de autocontrole baseadas em argumentos mentalistas ou de cunho biológico não levam em consideração os determinantes ambientais do comportamento. Identificar esses determinantes é importante, pois é a partir da manipulação dos mesmos que mudanças comportamentais são obtidas (Skinner, 1953/2003).

Para Skinner (1953/2003) o indivíduo passa a controlar parte do seu comportamento quando se defronta com consequências conflituosas, as quais envolvem tanto reforçamento positivo quando punição. Por exemplo, dormir até mais tarde pode gerar consequências reforçadoras positivas, como boa disposição e melhor saúde; no entanto, também pode trazer consequências aversivas, como chegar atrasado para os compromissos e receber advertência do chefe. Diante desse conflito, a resposta punida (dormir até mais tarde) pode ser enfraquecida ao alterar algumas variáveis das quais essa resposta é função (e.g., ir para a cama mais cedo na noite anterior, colocar o despertador longe da cama). Nesse caso, Skinner denomina a resposta punida de 'resposta controlada', e a resposta que promove seu enfraquecimento, de 'resposta controladora'.

Todos os dias, emitimos respostas controladoras em diferentes contextos. Uma pessoa que evita entrar em uma loja de chocolates por causa da dieta está emitindo uma resposta controladora; essa resposta diminui a probabilidade de emissão da resposta controlada (comer chocolate) e, assim, evita suas consequências aversivas (e.g., engordar). Um aluno que apresenta baixo desempenho acadêmico porque passa muito tempo no 
aplicativo WhatsApp (resposta controlada) poderia desativar esse aplicativo (resposta controladora). É importante enfatizar que a resposta controladora somente será mantida se diminuir a probabilidade da ocorrência da resposta controlada. Em ambos os exemplos, a resposta controlada tem consequências reforçadoras imediatas (sabor do chocolate, conversa virtual com amigos) e consequências aversivas atrasadas (engordar, notas baixas), enquanto a resposta controladora tem consequências reforçadoras atrasadas (manter o corpo saudável e bonito, ter um bom desempenho acadêmico) e consequências aversivas imediatas (não saborear o chocolate, ficar de fora da conversa com os amigos). Para que a resposta controladora ocorra, então, é necessário que produza um ganho líquido maior do que aquele produzido pela resposta controlada (Moreira \& Abreu-Rodrigues, 2008).

Baseado na proposta conceitual de Skinner (1953/2003), Rachlin (1974) propôs um procedimento para investigar experimentalmente o autocontrole. Nesse procedimento (daqui em diante chamado de procedimento de Rachlin), o organismo tem duas alternativas de escolha conflituosas: uma delas gera reforços imediatos, mas de menor magnitude (elo terminal de impulsividade - IP), enquanto a outra produz reforços atrasados, porém de maior magnitude (elo terminal de autocontrole - AC). O modelo também prevê a escolha entre duas alternativas punitivas: no elo terminal de IP, os punidores têm maior magnitude, mas são atrasados; no elo terminal de AC, embora sejam imediatos, os punidores têm menor magnitude. Um exemplo do procedimento de Rachlin seria expor um rato a uma escolha entre receber uma pelota de comida imediatamente ou três pelotas após $10 \mathrm{~s}$ (ou receber um choque por $5 \mathrm{~s}$ após $10 \mathrm{~s}$ ou receber um choque por $0,5 \mathrm{~s}$ imediatamente). Uma escolha relativa maior pelos reforços de maior magnitude, porém atrasados, ou pelos punidores imediatos, mas de menor magnitude, indicaria escolha relativa pelo elo terminal de AC. 
Um procedimento similar foi desenvolvido por Mischel e Ebbesen (1970). Nesse procedimento, denominado de atraso da gratificação, o organismo é exposto a uma situação em que um reforço atrasado e de maior magnitude é programado. Há duas opções: esperar pela apresentação desse reforço (alternativa AC) ou, durante o período de espera, emitir uma resposta que cancela esse reforço e produz imediatamente um reforço de menor magnitude (alternativa IP). Aqui, a medida de AC consiste no tempo de espera, o qual é contado a partir do início do atraso e finalizado com o recebimento do reforço atrasado ou com a emissão da resposta que produz o reforço imediato. Quanto maior o tempo de espera, maior o AC.

Finalmente, AC também tem sido investigado por meio do procedimento do desconto do atraso. Em sua versão padrão, esse procedimento utiliza como reforçadores valores monetários hipotéticos ou reais e investiga a desvalorização desses reforçadores em função do atraso (Mazur, 1987). O valor monetário para o reforçador atrasado é sempre fixo, enquanto que para os reforçadores imediatos, esse valor é manipulado. Por exemplo, é perguntado ao participante se ele prefere (hipoteticamente) receber $\mathrm{R} \$ 1.000,00$ agora ou $\mathrm{R} \$ 1.000,00$ daqui a uma semana, sendo esperado que o participante escolha $\mathrm{R} \$ 1.000,00$ agora. Em seguida, é perguntado ao participante se ele prefere receber $\mathrm{R} \$ 900,00$ agora ou $\mathrm{R} \$ 1.000,00$ daqui a uma semana; $\mathrm{R} \$ 800,00$ agora ou $\mathrm{R} \$ 1.000,00$ daqui a uma semana, e assim por diante, até o valor do reforçador imediato ser, por exemplo, $\mathrm{R} \$ 1,00$. $\mathrm{O}$ procedimento, então, é repetido com diferentes atrasos (e.g., um mês, seis meses, um ano, três anos, cinco anos). Para cada um dos valores de atraso é registrado o ponto de indiferença, ou seja, o valor do reforço imediato na alternativa em que o organismo passa a preferir o reforço atrasado, o qual indica o desconto do atraso. Por exemplo, a mudança na escolha quando o valor do reforço imediato é igual a $\mathrm{R} \$ 700,00$ mostra uma desvalorização 
de 30\% do reforço atrasado. Quanto menor a desvalorização do reforço decorrente do atraso, maior o AC.

Nos três procedimentos acima descritos, duas variáveis são simultaneamente manipuladas: o atraso e a magnitude do reforço. Em alguns arranjos dessas variáveis, o comportamento mais eficiente é escolher a alternativa IP (e.g., Flora \& Pavlik, 1992; Green \& Synderman, 1980; Rachlin \& Green, 1972) e, em outros, escolher a alternativa AC (e.g., Flora \& Pavlik, 1992; Green, Fisher, Perlow \& Sherman, 1981; Snyderman, 1983). Nas situações em que o comportamento mais eficiente é escolher reforços de maior magnitude, embora atrasados, escolhas impulsivas têm sido correlacionadas com diversos problemas clínicos, tais como déficit de atenção, hiperatividade e uso de drogas. Dadas as limitações cotidianas impostas por esses problemas, diversos estudos têm buscado identificar suas variáveis de controle (e.g., Eisenberger \& Adornetto, 1986; Grosh \& Neuringer, 1981; Lima, 2011; Logue, Peña-Correal, Rodrigues \& Cabela, 1986; Mischel, Ebbesen \& Zeis, 1972; Rachlin, Rainere \& Cross, 1991; Snyderman, 1983). O controle temporal, uma das variáveis identificadas (e.g., Church \& Deluty, 1977; Darcheville, Riviere \& Wearden, 1992; Smith, Marshall \& Kirkpatrick, 2015), consistiu no foco do presente trabalho. Mais precisamente, objetivou-se verificar possíveis relações entre discriminação/controle temporal e escolha entre IP e AC por meio do procedimento proposto por Rachlin (1974).

$\mathrm{Na}$ breve revisão da literatura que se segue, serão descritos alguns determinantes da escolha entre IP e AC. Em seguida, a variável controle temporal será destacada, sendo apresentados os principais procedimentos experimentais utilizados para avaliar seus efeitos. Finalmente, será descrita a justificativa do presente trabalho. 


\section{VARIÁVEIS QUE AFETAM A ESCOLHA POR AUTOCONTROLE}

O procedimento proposto por Rachlin (1974) para estudar autocontrole consiste em um esquema concorrente encadeado. Nos elos iniciais, usualmente, vigoram esquemas de intervalo variável (VI), programados concorrentemente (conc VI VI) em dois operanda. Dessa forma, após a passagem do intervalo, a primeira resposta inicia um dos elos terminais (IP ou AC), dependendo do operandum em que essa resposta foi emitida. Quando o elo terminal de IP é escolhido, um reforço de menor magnitude é liberado após um atraso curto, e quando o elo terminal de $\mathrm{AC}$ é escolhido, um reforço de magnitude maior é apresentado ao término de um atraso longo. Em ambos os casos, o reforço pode ou não ser seguido por um intervalo entre tentativas (IET), ao final do qual uma nova tentativa ocorre.

Quando os esquemas concorrentes são programados independentemente, há um contador de tempo específico para cada esquema e, assim, a primeira resposta que cumprir as exigências do esquema, a despeito do operandum em que a resposta for emitida, inicia o elo terminal correspondente àquele operandum. Com essa programação, o menor atraso e o menor tempo de acesso ao reforço no elo terminal de IP produzem uma maior taxa de reforços nesse elo, o que pode gerar viés e, até mesmo, escolha exclusiva, em favor do mesmo.

Para evitar esse problema, alguns autores (e.g., Beeby \& White, 2013; Moreira \& Abreu-Rodrigues, 2008; Snyderman, 1983) têm programado os esquemas concorrentes de forma dependente. Nesse caso, há apenas um contador de tempo para os esquemas em vigor nos elos iniciais e a decisão de qual elo terminal ocorrerá a cada tentativa é feita previamente pelo experimentador. Ou seja, o elo terminal só é produzido quando, após o cumprimento das exigências do esquema, o organismo emite uma resposta no operandum correlacionado com o elo terminal selecionado, pelo experimentador, para aquela tentativa. 
Assim, programando-se um número igual de ocorrências dos elos terminais de IP e AC, o número de reforços obtidos também não difere entre esses elos. Adicionalmente, com o objetivo de produzir elos com durações similares, um período de blackout (BO) é adicionado após o reforço em ambos os elos terminais, sendo esse BO mais longo no elo terminal de IP. Em conjunto, essas estratégias (programação dependente e BO) geram taxas de reforços similares entre os elos terminais.

A literatura tem identificado alguns determinantes da escolha de AC, tais como: atraso do reforço (e.g., Beeby \& White, 2013; Snyderman, 1983), magnitude do reforço (e.g., Logue \& cols., 1986; Marshall \& Kirkpatrick, 2016), probabilidade do reforço (e.g., Rachlin \& cols., 1991), atividade durante o atraso (e.g., Grosh \& Neuringer, 1981; Mischel \& cols.,1972; Moreira \& Abreu-Rodrigues, 2008), visualização do reforço (e.g., Grosh \& Neuringer, 1981; Mischel \& Ebbesen, 1970), história experimental (e.g., Eisenberger \& Adornetto, 1986; Renda \& Madden, 2016) e exposição a drogas (e.g., Barbosa, 2010; Lima, 2011). Todos desses estudos serão descritos a seguir, de modo a ilustrar o papel de cada um dos determinantes da escolha entre IP e AC. ${ }^{1}$

Duração do atraso. No estudo de Snyderman (1983), pombos foram expostos a um esquema concorrente encadeado para investigar o efeito de diferentes durações do atraso do reforço sobre a escolha entre AC e IP. Nos elos iniciais vigorava o esquema conc VI 60 s VI 60 s com programação dependente. No elo terminal de AC, o reforço consistiu em $6 \mathrm{~s}$ de acesso à comida, e no elo terminal de IP, 2 s. Na condição 6:1, os atrasos de AC e IP eram 12 e 2 s, 60 e 10 s, 120 e 20 s, respectivamente; na condição 3:1, os atrasos eram 6 e 2 s, 30 e 10, 60 e 20 s, 120 e 40 s, respectivamente; e na condição 3:2, os atrasos eram 6 e 4 s, 60 e 40 s, 120 e 80 s, respectivamente. Dessa forma, os valores dos atrasos absolutos foram manipulados intracondição e os valores dos atrasos relativos foram manipulados entre condições. Havia um BO após o reforço em ambos os elos terminais, de modo a

\footnotetext{
${ }^{1} \mathrm{Na}$ descrição dos estudos a seguir, o tipo de programação só será destacado caso tenha sido dependente.
} 
igualar a duração desses elos. Foi observado que a taxa relativa de respostas no elo inicial correlacionado com AC diminuiu com os aumentos nos atrasos absolutos, a despeito dos atrasos relativos. No entanto, essas diminuições foram mais acentuadas com atrasos relativos maiores.

Beeby e White (2013) também investigaram o efeito da exposição a diferentes atrasos sobre a escolha de AC. No Experimento 1, pombos foram expostos a um esquema múltiplo com dois componentes (vermelho e verde). Em ambos os componentes estava em vigor um esquema concorrente encadeado. Nos elos iniciais vigorava o esquema conc VI 15 s VI 15 s dependente. Nos elos terminais, operava um esquema de intervalo fixo (FI) durante o atraso. No componente vermelho estava em vigor a condição $T=0$, durante a qual os valores do esquema FI correspondiam a $1 \mathrm{~s}$ no elo terminal de IP e a $10 \mathrm{~s}$ no elo terminal de AC. No componente verde, as condições variaram de $\mathrm{T}=1$ a $\mathrm{T}=10$, sendo que o valor de T representa o aumento (em segundos) no valor do FI em ambos os elos terminais em relação aos valores usados no componente vermelho (1 e 10 s). Em todas as condições, a magnitude do reforço foi $1,5 \mathrm{~s}$ e $4,5 \mathrm{~s}$ nos elos terminais de IP e AC, respectivamente. Havia um BO após a ocorrência do reforço em ambos os elos. A manipulação intrassessão no valor do atraso gerou resultados opostos àqueles obtidos por Snyderman. Ou seja, no componente vermelho, as escolhas relativas de IP predominaram, e no componente verde, aumentos nos valores absolutos dos atrasos produziram aumentos nas escolhas relativas de AC. Beeby e White não apresentaram uma justificativa para a inconsistência entre seus resultados e aqueles de Snyderman, mas é possível que, além das diferenças na forma de manipulação dos valores absolutos dos atrasos (intrassessão e intracondição), a diferença entre os valores absolutos utilizados por esses autores tenha contribuído para essa inconsistência. No estudo de Beeby e White, a diferença foi de, no máximo, 10 s, enquanto no estudo de Snyderman, essa diferença chegou a $100 \mathrm{~s}$. 
Magnitude do reforço. Logue e cols. (1986) avaliaram não somente os efeitos do atraso, mas também da magnitude do reforço sobre a escolha. Nesse estudo, estudantes universitários foram expostos a esquemas concorrentes encadeados nos experimentos 1 e 4, os quais se diferenciavam em termos dos esquemas em vigor nos elos iniciais e dos valores dos atraso e das magnitudes do reforço nos elos terminais. No Experimento 1, nos elos iniciais vigorava o esquema concorrente razão fixa 1 razão fixa 1 (conc FR 1 FR 1). Ou seja, a primeira resposta emitida iniciava o elo terminal correspondente ao operandum escolhido. Nos elos terminais (X e Y), os pares de magnitudes foram 10 e 10, 12 e 8, e 8 e 12 pontos, e os pares de atrasos foram 0,5 e $0,5 \mathrm{~s} ; 120$ e $0,5 \mathrm{~s} ; 0,5$ e $120 \mathrm{~s}$, respectivamente. No Experimento 4, o esquema conc VI 30 s VI 30 s vigorava nos elos iniciais. Isto é, a primeira resposta, após $30 \mathrm{~s}$, em média, iniciava o elo terminal correspondente ao operandum escolhido. Nos elos terminais X e Y, cada sujeito foi exposto a três pares de magnitude ( 6 e 6,10 e 2, e 2 e 10 pontos) e a três pares de atraso (os pares 6 e 6 s, 10 e 2 s, e 2 e $10 \mathrm{~s}$ foram comuns a todos os sujeitos e os outros dois foram específicos de cada sujeito). Em algumas condições experimentais, os atrasos nos dois elos terminais permaneciam constantes, enquanto as magnitudes eram manipuladas; em outras condições, ocorria o inverso; finalmente, havia condições em que tanto os atrasos quanto as magnitudes variavam conjuntamente. Um BO foi adicionado após a liberação do reforço de modo que cada tentativa ocorria a cada 3 min. Os resultados de ambos os experimentos mostraram que, quando o atraso foi mantido constante, a escolha pelo elo terminal com maior magnitude foi mais frequente, e quando a magnitude foi mantida constante, a escolha pelo elo terminal com menor atraso predominou. Por outro lado, quando atraso e magnitude variaram juntos, as escolhas foram mais sensíveis à magnitude do reforço, ou seja, o elo terminal com reforço de maior magnitude (elo terminal de AC) foi escolhido mais frequentemente, independentemente do atraso. Importante ressaltar que esse resultado 
não é comumente observado com não humanos e crianças, os quais tendem a escolher predominantemente o elo terminal de IP (cf., Ainslie, 1975; Mischel \& Ebbesen 1970; Rachlin \& Green, 1972). Uma das explicações para tal diferença é o fato de que, em estudos com humanos adultos, a consequência é um reforço secundário (e.g., pontos), normalmente ‘consumido' somente após o final da sessão (troca por dinheiro), enquanto em estudos com crianças e não humanos, a consequência é um reforço primário (e.g., alimento) e seu consumo é realizado durante a sessão experimental. Essa explicação parece viável quando se considera o estudo de Hackenberg e Vaidya (2003), no qual foi observado, com pombos, preferência por AC quando reforços secundários foram usados.

Marshall e Kirkpatrick (2016, Experimento 2) investigaram se um treino discriminativo da magnitude do reforço aumentaria o controle exercido por essa variável. Na primeira condição, ratos foram expostos ao procedimento de Rachlin. Nos elos iniciais estava em vigor o esquema conc FR1 FR 1. Se a primeira resposta ocorresse na barra correlacionada com o elo terminal de IP, havia um atraso de $10 \mathrm{~s}$ seguido pela liberação de uma pelota de comida; se a barra correlacionada com o elo terminal de AC fosse pressionada, havia um atraso de $30 \mathrm{~s}$ seguido de duas ou quatro pelotas de comida, nas fases 1 e 2, respectivamente. Após a liberação do reforço em ambos os elos terminais, um IET de 60 s era iniciado. Na segunda condição, os sujeitos foram expostos a uma tarefa de discriminação da magnitude do reforço. No início da tentativa, as duas barras estavam disponíveis. A primeira resposta em uma das barras retraía a outra e a próxima resposta na barra que ficou disponível produzia o reforço, o qual era seguido pelo IET. Para o grupo controle, ambas as barras disponibilizavam duas pelotas. Para o grupo intervenção, a barra que foi correlacionada com IP, na condição anterior, disponibilizava uma pelota, enquanto a barra que foi correlacionada com AC disponibilizava duas ou quatro pelotas, nas fases 1 e 2, respectivamente. $\mathrm{Na}$ terceira condição, os sujeitos foram expostos novamente ao 
procedimento de Rachlin. Os resultados mostraram que a escolha relativa de $\mathrm{AC}$ aumentou para o grupo intervenção, o qual passou pelo treino de discriminação da magnitude. Os aumentos foram maiores na fase 2 , em que a magnitude do reforço no elo terminal de AC foi quatro vezes maior (4:1) do que no elo terminal de IP.

Probabilidade do reforço. Rachlin e cols. (1991) investigaram essa variável, além do atraso, por meio do procedimento do desconto. Estudantes universitários foram distribuídos em dois grupos: atraso e probabilidade. Em ambos os grupos, os participantes deveriam escolher entre dois cartões. O cartão relacionado ao ganho imediato (grupo atraso) ou certo (grupo probabilidade) mudava a cada tentativa e incluía 30 valores entre US\$1000,00 e US\$1,00. Para o grupo atraso, o outro cartão referia-se a um ganho fixo de US\$1000,00 com 1 mês, 6 meses, 1, 5, 10, 25 e 50 anos de atraso. Para o grupo probabilidade, o outro cartão correspondia a um ganho fixo de US\$1000,00 com 95, 90, $70,50,30,10$ e $5 \%$ de probabilidade. Os resultados indicaram maiores descontos para reforços muito atrasados ou pouco prováveis, ou seja, preferência pelo ganho imediato ou certo, respectivamente. Entretanto, à medida que o atraso diminuiu ou a probabilidade aumentou, houve reversão na preferência (menor desconto). Os autores sugerem que o atraso e a probabilidade do reforço afetam a escolha de maneira semelhante, pois a relação entre desconto e atraso (ou probabilidade) do reforço foi adequadamente descrita por uma função hiperbólica em ambos os casos (ver também Navarick, 1987; Rachlin, Castrogionvanni \& Cross, 1987). Essa similaridade entre os efeitos do atraso e da probabilidade do reforço, no entanto, nem sempre é observada (ver Coelho, Hanna \& Todorov, 2003; Yi \& Bickel, 2005).

Atividades durante o atraso. No estudo de Mischel e cols. (1972, Experimento 1), com o procedimento de atraso da gratificação, crianças foram distribuídas em cinco grupos. Durante o atraso do reforço de maior magnitude, as crianças eram solicitadas a 
brincar com um brinquedo (atividade pública - grupos 1 e 4) ou a pensar em alguma coisa agradável (atividade encoberta - grupos 2 e 5), enquanto as crianças do Grupo 3 não foram solicitadas a realizar nenhuma atividade durante o atraso. As crianças que realizaram atividades durante o atraso apresentaram um maior tempo de espera do que aquelas sem atividade, a despeito da atividade ser pública ou encoberta. Ao utilizarem um procedimento comparável, com pombos, Grosh e Neuringer (1981, Experimento 2) observaram que, quando um disco adicional era iluminado durante o atraso, os animais apresentaram um maior tempo de espera do que na ausência desse disco, havendo ou não reforços contingentes às respostas nesse disco. Finalmente, resultados similares foram obtidos por Moreira e Abreu-Rodrigues (2008) quando expuseram pombos ao procedimento de Rachlin. Na condição LB, não havia exigência de sequências de respostas durante o atraso; na condição VAR, os animais tinham que emitir sequências variadas de respostas; e na condição ACO, sequências de respostas tinham que ser emitidas, mas não havia exigência de variação. Foi observado que o número relativo de escolhas por autocontrole foi maior quando havia atividade durante o atraso, independentemente da presença ou ausência da exigência de variação.

Visualização do reforço. Os efeitos dessa variável, observados a partir do procedimento de atraso da gratificação, foram relatados por Mischel e Ebbesen (1970) e por Grosh e Neuringer (1981, Experimento 1). No estudo de Mischel e Ebbesen, crianças mostraram um tempo de espera menor quando era possível visualizar os reforços (maior magnitude e menor magnitude) durante o atraso, principalmente quando ambos estavam visíveis simultaneamente, do que quando nenhum deles era visível. Similarmente, Grosh e Neuringer observaram que pombos esperaram pelo reforço por um período mais curto quando ambos os reforços estavam disponíveis visualmente em comparação com uma situação em que ambos estavam ausentes. 
História experimental. No estudo de Eisenberger e Adornetto (1986), 88 crianças foram distribuídas em cinco grupos: tarefa fácil e reforço imediato, tarefa fácil e reforço atrasado, tarefa difícil e reforço imediato, tarefa difícil e reforço atrasado e sem treino. As tarefas envolveram contar objetos, memorizar imagens e encaixar objetos em buracos com formas correspondentes. $\mathrm{O}$ que determinava se a tarefa era fácil ou difícil era o número de objetos e imagens utilizados na execução da tarefa. Os reforços eram moedas, as quais poderiam ser recebidas logo após o término da tarefa ou no final do turno escolar. Após a exposição às tarefas, todas as crianças foram expostas a duas situações de escolha: na situação A, a criança deveria indicar se preferia receber duas moedas agora (IP) ou receber três moedas ao final do dia (AC); na situação B, se preferia esperar $60 \mathrm{~s}$ para receber duas moedas (IP) ou realizar uma determinada atividade (copiar palavras sem sentido) por $60 \mathrm{~s}$ para receber três moedas (AC). Foi observado que as crianças com história de tarefa fácil e reforço atrasado apresentaram maior preferência por $\mathrm{AC}$ na situação $\mathrm{A}$, enquanto as crianças com história de tarefa difícil e reforço imediato apresentaram maior preferência por AC na situação B. Para os demais grupos, as escolhas por AC foram infrequentes ou similares às escolhas por IP. Esses resultados mostraram que histórias com diferentes atrasos e tarefas afetam diferencialmente as escolhas por AC.

Em um estudo recente, Renda e Madden (2016) investigaram se os efeitos da história com diferentes atrasos se manteriam após um longo intervalo. Na primeira condição, ratos foram distribuídos em dois grupos: exposição imediata (EI) e exposição atrasada (EA). Para ambos os grupos, pressionar a barra do fundo da câmara experimental produzia duas pelotas de alimento. No entanto, para o grupo EI, o reforço era imediato, enquanto para o grupo EA, o reforço era fornecido após um atraso de 17,5 s. Na segunda condição, todos os sujeitos foram expostos, inicialmente, a sessões de discriminação da magnitude do reforço, durante as quais escolhiam entre uma e três pelotas, liberadas 
imediatamente após uma resposta de pressionar a barra esquerda ou direita do painel principal, respectivamente. Após os sujeitos escolherem três pelotas em, pelo menos, $90 \%$ das tentativas, por duas sessões consecutivas, foi iniciada a terceira condição, durante a qual foi utilizado o procedimento de Rachlin. Nos elos iniciais do esquema concorrente encadeado vigorava o esquema conc FR1 FR1. O reforço consistia em uma pelota de alimento no elo terminal de IP e em três pelotas no elo terminal de AC. Em ambos os elos, as pelotas eram liberadas imediatamente até que as escolhas de AC predominassem por duas sessões consecutivas. Em seguida, o atraso de AC foi manipulado intrassessão, ou seja, atrasos de 0,15 e $30 \mathrm{~s}$ foram programados, nesta ordem, entre blocos de tentativas. Após a liberação do reforço, um BO foi adicionado, de modo que cada tentativa ocorria a cada 90 s. A cada sete sessões de escolha entre IP e AC ocorria uma sessão de discriminação da magnitude do reforço. Após 120 dias do término da terceira condição, foi feito um reexposição às sessões de discriminação e à escolha entre IP e AC. Os resultados demonstraram que a escolha relativa de AC foi maior para os animais do grupo EA do que para aqueles do grupo EI, a despeito dos valores do atraso de AC na tarefa de escolha (exceto quando o atraso era igual a $0 \mathrm{~s}$ nos dois elos terminais; nesse caso, ambos os grupos apresentaram escolha exclusiva por AC), e que essa diferença entre os grupos se manteve mesmo após 120 dias de intervalo. Ou seja, história com atrasos longos promoveu escolhas por AC, mesmo após longos períodos de tempo.

Uso de droga. O estudo de Lima (2011, Experimento 1) avaliou, com ratos, os efeitos da exposição ao álcool durante o período da adolescência. Havia dois grupos: probabilidade/álcool (PA) e probabilidade/controle (PC). Inicialmente, os sujeitos do grupo PA consumiram uma solução de gelatina com $10 \%$ de álcool; os sujeitos do grupo PC consumiram a mesma solução de gelatina, mas sem álcool. Após três semanas do final dessa fase, todos os sujeitos foram expostos ao procedimento de Rachlin, no qual vigorava, 
nos elos iniciais, o esquema conc VI 10 s VI 10 s. Nos elos terminais, o sujeito poderia receber uma solução com 5\% de sacarose e probabilidade de ganho igual a 1,0 (elo terminal de IP) ou uma solução com $20 \%$ de sacarose e probabilidade variada de ganho (elo terminal de AC). Essa probabilidade variava entre 10, 25, 50, 75 ou $90 \%$ ao longo das sessões, de maneira randômica, de modo que todos os sujeitos foram expostos a aproximadamente 15 sessões com cada valor de probabilidade. Para os dois grupos, quanto menor a probabilidade do reforço, menor a escolha relativa do elo terminal de AC, a despeito do reforço sempre apresentar maior magnitude nesse elo do que no elo terminal de IP. No entanto, a escolha relativa pelo elo terminal de AC foi menos acentuada para o grupo PA do que para o grupo PC, o que sugere que a história com álcool promoveu maior sensibilidade à probabilidade do reforço do que a história sem álcool.

O estudo de Barbosa (2010) investigou a desvalorização pelo atraso, tanto em contingências positivas quanto em contingências aversivas, envolvendo valores monetários hipotéticos. Os participantes - fumantes, fumantes em tratamento e não fumantes escolhiam entre um reforço imediato e um reforço atrasado (receber um determinado valor monetário hipotético) ou uma punição imediata ou atrasada (pagar um determinado valor monetário hipotético). O valor monetário hipotético atrasado era sempre fixo $(\mathrm{R} \$ 1.000,00)$ e os valores imediatos variaram de $R \$ 1,00$ a $R \$ 1.000,00$. Os valores foram apresentados em ordem crescente e decrescente em blocos de 30 tentativas. Os atrasos foram 1 semana, 1 mês, 1 ano, 3 anos, 5 anos, 10 anos e 35 anos, apresentados sempre em ordem crescente. Os resultados demonstraram que o desconto do atraso foi similar, tanto nas contingências positivas quanto nas contingências aversivas. No entanto, nas contingências positivas, os fumantes apresentaram maior desconto do que os não fumantes e fumantes em tratamento, enquanto os fumantes em tratamento apresentaram um desconto intermediário. Nas contingências aversivas, o desconto foi similar, a despeito das diferenças no 
comportamento de fumar dos participantes. Barbosa concluiu que os fumantes mostraramse mais impulsivos em situações apetitivas, mas em situações aversivas, o nível de impulsividade não diferiu entre os grupos.

Outra variável que tem sido apontada como importante para escolha entre autocontrole e impulsividade é o controle temporal, o qual será discutido a seguir.

\section{CONTROLE TEMPORAL}

Segundo Catania (1991), controle temporal (em inglês, temporal control ou timing) refere-se ao controle do comportamento por alguma propriedade temporal do ambiente (e.g., passagem do tempo, duração de um estímulo). Os estudos sobre controle temporal avaliam processos comportamentais tais como regulação temporal, discriminação temporal e precisão temporal. Regulação temporal tem sido tradicionalmente investigada com esquemas FI e esquemas de reforçamento diferencial de taxas baixas (DRL). Nesse caso, o interesse recai sobre a distribuição da resposta ao longo do tempo. O processo de discriminação temporal, por sua vez, tem sido avaliado por meio de esquemas múltiplos com componentes temporais (e.g., esquema múltiplo FI FI) e de procedimentos de escolha de acordo com o modelo (e.g., procedimento de bissecção). Em ambos os casos, a evidência de discriminação temporal seria o responder diferencial diante de estímulos temporais diferentes. Finalmente, a precisão temporal é comumente analisada por meio da inclusão de tentativas de pico no esquema FI (procedimento de pico). Aqui, a variável de interesse é a proximidade entre o pico da taxa de respostas e o término do FI (Castro, Carvalho, Kroger-Costa \& Machado, 2013; Catania, 1991). Esses procedimentos e suas variáveis dependentes serão descritos a seguir.

Os estudos sobre controle temporal em situação de impulsividade e autocontrole têm utilizado diferentes estratégias metodológicas, utilizando procedimentos que envolvem 
regulação, discriminação ou precisão temporal. Quando a relação entre controle temporal e escolha entre IP e AC é investigada, em geral, observa-se que comportamentos impulsivos decorrem de controle temporal deficiente (Barratt, 1983; Baumann \& Odum, 2012; Darcheville \& cols., 2002; Marshall \& cols., 2014; McClure, Podos \& Richardson, 2014; Van Den Broek, Bradshaw \& Szabadi, 1991), conforme será apresentado a seguir.

Intervalo fixo (FI). Em esquemas FI, a primeira resposta emitida após a passagem de um intervalo específico de tempo produz a liberação do reforço; respostas emitidas antes do fim desse intervalo não produzem reforços (Zeiler \& Powell, 1994). Por exemplo, no caso de um esquema FI $15 \mathrm{~s}$, apenas a primeira resposta emitida após $15 \mathrm{~s}$ desde o início do intervalo é seguida pelo reforço. Nesse esquema, a taxa de respostas é tipicamente baixa no início do intervalo (quando o reforço é improvável), podendo haver pausas (ausência de respostas) logo após o reforço, mas à medida que o final do intervalo se aproxima (e a probabilidade do reforço aumenta), as taxas de respostas aumentam (Catania,1991). Esse tipo de distribuição das respostas ao longo do intervalo, denominado de padrão scallop, revela controle pela passagem do tempo (Harzem, Lowe \& Spencer (1978).

No estudo de Darcheville e cols. (1992), 16 crianças foram expostas a esquemas FI e, em seguida, à escolha entre IP e AC (para metade dos participantes, a ordem foi inversa). Quando o esquema FI estava em vigor, a primeira resposta de pressionar um botão, emitida após a passagem do intervalo, produzia desenhos animados por $20 \mathrm{~s}$. Os valores do FI variaram entre 10 e $80 \mathrm{~s}$ ao longo das sessões. Na situação de escolha foi utilizado o procedimento de Rachlin. Nos elos iniciais estava em vigor o esquema conc FR 1 FR 1. No elo terminal de IP, pressionar um botão gerava um atraso de $0,5 \mathrm{~s}$, após o qual um desenho animado era apresentado por $20 \mathrm{~s}$; no elo terminal de AC, pressionar outro botão iniciava um atraso de $40 \mathrm{~s}$, seguido pela apresentação do desenho animado por $40 \mathrm{~s}$. 
Ao final da apresentação do reforço, um BO de duração variada ocorria com o objetivo de igualar a duração das tentativas (90 s). Os resultados obtidos mostraram uma correlação entre o desempenho no esquema FI e a escolha relativa de AC: as crianças que responderam em taxas altas no FI e não apresentaram pausa pós-reforço, escolheram prioritariamente o elo terminal de IP, enquanto as crianças que apresentaram um desempenho eficiente no esquema FI, ou seja, que responderam em taxas baixas e produziram pausa pós-reforço, apresentaram preferência por AC. No entanto, uma variável não diretamente manipulada pode também ter contribuído para os resultados, a saber, a execução de atividades durante o atraso (veja Grosh \& Neuringer, 1981; Mischel \& cols., 1972; Moreira \& Abreu-Rodrigues, 2008). Ao final do estudo, algumas crianças que escolheram predominantemente $\mathrm{AC}$ revelaram que contaram números ou cantaram músicas durante o atraso.

Em um estudo similar, Smith e cols. (2015, Experimento 2) também investigaram a relação entre a exposição a esquemas FI e a escolha entre IP e AC. Mas, ao contrário do estudo de Darcheville e cols. (1992), o qual permitiu apenas a identificação de correlações entre controle temporal e escolha de AC, no estudo de Smith e cols. foi possível a identificação de relações causais entre essas variáveis. Vinte e quatro ratos foram expostos a três fases: escolha pré-intervenção, intervenção e escolha pós-intervenção. Na fase de escolha pré-intervenção, os animais foram expostos ao procedimento de Rachlin. Durante os elos iniciais estava em vigor o esquema conc FR 1 FR 1 . No elo terminal de IP, pressionar a barra esquerda iniciava um atraso de 5, 10 ou 20 s (condições 1 a 3, respectivamente), após o qual era apresentada uma pelota de alimento. No elo terminal de AC, pressionar a barra direita ocasionava um atraso de $30 \mathrm{~s}$ e duas pelotas de alimento. Ao final da entrega do reforço em ambos os elos terminais, um IET de $120 \mathrm{~s}$ ocorria. Na fase de intervenção, os sujeitos foram expostos aos esquemas FI 10 s e FI 30 s. O reforço 
consistiu em uma pelota para o intervalo menor (10 s) e duas pelotas para o intervalo maior (30 s). Inicialmente, os dois esquemas FI foram apresentados em sessões alternadas durante 30 sessões. Em seguida, foram realizadas 20 sessões com o FI 10 s e 20 sessões com o FI 30 s, sendo que a ordem de exposição a esses esquemas variou entre os sujeitos. A fase de escolha pós-intervenção foi similar à primeira fase. Foi observado que a intervenção com o esquema FI produziu aumento nas escolhas relativas de $\mathrm{AC}$, principalmente quando o atraso no elo terminal de IP era $5 \mathrm{~s}$.

Procedimento de pico. Nesse procedimento, desenvolvido por Catania (1970), tentativas de sondagem são adicionadas às tentativas FI. As tentativas de sondagem não incluem a apresentação do reforço e, geralmente, têm uma duração duas vezes maior do que o valor do FI. Observa-se, comumente, que a taxa de respostas atinge seu valor máximo (pico) em um ponto do intervalo que não ultrapassa mais que $10 \%$ do valor do FI e que, em seguida, há uma desaceleração no responder. Por exemplo, no estudo de Zeiler e Powell (1994), pombos foram expostos a um esquema FI, com valores de 7,5, 15, 30 60, 120 e 480 s. Cada valor do FI esteve em vigor por 15 sessões consecutivas, sendo uma sessão encerrada após a ocorrência de 60 tentativas. Dentre essas 60 tentativas, $25 \%$ eram tentativas de pico, com o dobro da duração das tentativas FI e sem reforços. Foi observado que, quanto maior o valor do FI, mais longa a pausa pós-reforço e mais tarde no intervalo ocorreu o pico de respostas, indicando o desenvolvimento de controle temporal.

Galtress, Garcia e Kirkpatrick (2012, Experimento 1) realizaram um estudo correlacional, no qual tentativas de pico foram adicionadas ao procedimento de Rachlin. Quatro grupos de seis ratos cada, foram expostos a um esquema concorrente encadeado, durante o qual vigorava, nos elos iniciais, o esquema conc FR 1 FR 1. Nos elos terminais, a duração do atraso variou entre os grupos, sendo 5 e 15 s, 5 e 20 s, 10 e 30 s e 15 e 30 s, nos elos terminais IP e AC, para os grupos 1, 2, 3 e 4, respectivamente. A magnitude do 
reforço correspondeu a uma pelota de comida no elo terminal de IP e a duas pelotas de comida no elo terminal de AC. As sessões foram divididas em quatro blocos de tentativas e cada bloco foi composto pela apresentação randômica de 16 tentativas de escolha forçada (i.e., apenas um dos elos terminais estava disponível), 30 tentativas de escolha livre (i.e., os dois elos terminais estavam disponíveis) e quatro tentativas de pico (i.e., apenas a barra correlacionada com os elos terminais de AC ou de IP estava disponível, mas não havia liberação do reforço e a tentativa era finalizada após 90 s). Cada tentativa foi separada por um IET de 120 s. Quanto maior a diferença entre os atrasos absolutos de IP e de AC, maior a porcentagem de escolhas de IP (exceto para os atrasos de 15 e 30 s), o que é consistente com os achados de Snyderman (1983). Para a maioria dos sujeitos, nas tentativas de pico, taxas de respostas mais altas ocorreram próximo ao valor do atraso de IP e de AC e o período de transição de taxas baixas para taxas altas de respostas (e vice-versa) variou diretamente com o aumento nos atrasos absolutos. No entanto, as correlações entre as medidas de precisão temporal (pico da taxa de respostas e período de transição) e a porcentagem de escolha de IP, além de baixas ( $r$ menor ou igual a 0,2 ), não foram estatisticamente significativas. As autoras afirmam que a falta de correlação pode ter ocorrido em função do delineamento experimental, uma vez que os animais foram distribuídos em grupos e cada grupo foi exposto a apenas um par de atrasos.

Resultados inconsistentes com os de Galtress e cols. (2012) foram relatados no estudo de Smith e cols. (2015, Experimento 2), descrito acima. Nesse experimento, durante a apresentação das tentativas de escolha de IP e AC na fase pré- e pós-intervenção, foram adicionadas tentativas de pico com o objetivo de investigar se a intervenção com esquemas FI poderia favorecer a precisão temporal e, assim afetar as escolhas entre IP e AC. Durante as tentativas de pico, as barras de IP e de AC ficavam disponíveis por $90 \mathrm{~s}$ e não havia liberação de reforços. Os resultados indicaram que, antes da intervenção, os sujeitos 
respondiam próximo ao final da duração dos esquemas FI (10 ou 30 s), e que, após a intervenção com esses esquemas, foram observados acréscimos tanto na precisão temporal (taxa máxima de respostas aumentou, assim como sua proximidade com o valor do FI), quanto nas escolhas relativas de AC, sugerindo uma correlação entre essas variáveis (ver também, Marshall, Smith \& Kirkpatrick, 2014).

Reforçamento diferencial de taxas baixas (DRL). Nesse esquema, o reforço é liberado apenas quando uma resposta é emitida após a passagem de um determinado período de tempo (valor do DRL), contado desde o início da tentativa ou desde a emissão de uma resposta. Se uma resposta ocorrer antes do final desse período, a contagem de tempo é reiniciada a partir dessa resposta (Catania,1991; Fester \& Skinner, 1957). A propriedade temporal reforçada quando a contagem do valor do DRL é iniciada a partir de uma resposta é o intervalo entre respostas (IRT). A distribuição de frequências dos IRTs em pombos tende a ser bimodal, ou seja, comumente mostra uma predominância de IRTs curtos, combinados com IRTs próximos ao valor do DRL; ratos e humanos, no entanto, tendem a apresentar IRTs longos, iguais ou maiores que o valor do DRL. Já quando a contagem do valor do DRL é iniciada a partir do início da tentativa, a propriedade temporal é o período de tempo entre o início da tentativa e a emissão da resposta, sendo esse período sempre igual ou acima do valor do DRL (Catania, 1991).

Os efeitos da exposição ao esquema DRL sobre a escolha entre IP e AC foram avaliados no Experimento 1 do estudo de Smith e cols. (2015). As contingências em vigor nas fases pré- e pós-intervenção desse experimento foram idênticas às do Experimento 2, descrito anteriormente. Na fase de intervenção, entretanto, em vez de serem expostos aos esquemas FI, os sujeitos foram expostos a um esquema DRL. Havia três grupos: DRL $10 \mathrm{~s}$, DRL 30 s e DRL 10/30 s. Nos dois primeiros grupos, apenas um valor do DRL estava em vigor (10 ou $30 \mathrm{~s}$ ), enquanto no terceiro grupo, ambos os valores operavam (10 e $30 \mathrm{~s}$ ). 
Durante o DRL 10 s, o reforço consistia em uma pelota de comida, e durante o DRL 30 s, em duas pelotas de comida. Ao comparar as fases pré- e pós-intervenção, os autores observaram um aumento na precisão do controle temporal durante as tentativas de pico, assim como um aumento nas escolhas de AC. No entanto, os aumentos nas escolhas de AC foram menores do que aqueles obtidos no Experimento 2, no qual a intervenção foi realizada com esquemas FI.

Bissecção temporal. Esse procedimento, desenvolvido por Church e Deluty (1977), consiste em uma tarefa de escolha de acordo com o modelo, sendo o modelo a própria passagem do tempo. Nesse estudo, realizado com ratos, na fase de treino, a sessão era iniciada com a iluminação da caixa por 30 s. Em seguida, um dos estímulos modelo era apresentado, ou seja, a luz da caixa era apagada por diferentes períodos de tempo $(2 \mathrm{~s} \mathrm{em}$ metade das tentativas e $8 \mathrm{~s}$ nas demais tentativas). Após a apresentação de um dos estímulos modelo (curto ou longo), duas barras eram introduzidas na caixa (estímulos de comparação). Após o estímulo modelo curto, responder na barra esquerda produzia reforço (resposta correta), seguido de um IET de $30 \mathrm{~s}$, durante o qual a caixa era novamente iluminada; após o estímulo modelo longo, respostas na barra direita produziam as mesmas consequências (resposta correta). Responder na barra direita após o estimulo modelo curto e responder na barra esquerda após o estímulo modelo longo (respostas incorretas) produziam imediatamente o IET e a repetição da tentativa (procedimento de correção). Após $75 \%$ de acerto com cada estímulo, foi iniciada a fase de teste. Nessa fase, além dos estímulos modelo curto e longo (em $25 \%$ das tentativas), eram apresentados estímulos com durações intermediárias (em 75\% das tentativas). Essas durações eram 2,6; 3,2; 4,0; 5,0 e 6,4 s. Após a apresentação do estímulo modelo, os estímulos de comparação eram mostrados, mas as respostas não eram reforçadas quando os estímulos modelo correspondiam aos valores com duração intermediária. 
No procedimento de bissecção temporal, as variáveis dependentes são, normalmente, a porcentagem de acertos e a proporção de respostas. A porcentagem de acertos pode ser avaliada tanto na fase de treino quanto na fase de teste. Nesse último caso, essa porcentagem inclui apenas as respostas corretas após os modelos curto e longo. Usualmente, o critério de aprendizagem na fase de treino é $80 \%$ de acertos. Com relação à proporção de respostas, verifica-se a proporção de tentativas em que a barra correlacionada com o modelo longo (ou com o modelo curto) foi escolhida em função das durações dos estímulos modelos. Os resultados obtidos na fase de teste são representados por meio de uma função psicométrica, a qual apresenta duas importantes características (Castro \& cols., 2013): forma sigmoide e ponto de igualdade subjetiva. A forma sigmoide indica que a proporção de escolhas pela barra correlacionada com o modelo longo aumenta à medida que aumenta a duração dos estímulos modelo. O ponto de igualdade subjetiva (PIS), também denominado de ponto de bissecção ou ponto de indiferença, indica a duração do modelo que o sujeito considerou longo (ou curto) em 50\% das tentativas. Para animais não humanos, o PIS está próximo da média geométrica, enquanto que para animais humanos, o PIS é próximo da média aritmética. No estudo de Church e Deluty (1977) acima descrito, por exemplo, foi observado que: (1) à medida que a duração dos estímulos modelo aumentou, ocorreu um aumento na proporção de escolha da barra correlacionada com o estímulo longo; e (2) o ponto de bissecção $(4,03 \mathrm{~s})$ foi mais próximo da média geométrica $(4,00 \mathrm{~s})$ do que das médias aritmética $(5,00 \mathrm{~s})$ e harmônica $(3,20)$.

O procedimento de bissecção foi utilizado por Marshall e cols. (2014) para avaliar, com ratos, a correlação entre controle temporal e uma tarefa de escolha entre IP e AC. Durante a tarefa de escolha, foi utilizado um esquema concorrente encadeado. Nos elos iniciais vigorava o esquema conc FR 1 FR 1. Respostas na barra correlacionada com o elo terminal de IP produziam um atraso de 2,5; 5, 10 ou $30 \mathrm{~s}$, apresentados em fases separadas, 
seguido da liberação de uma pelota de comida; respostas na barra correlacionada com o elo terminal de AC eram seguidas por um atraso de 30 s, após o qual eram liberadas duas pelotas de comida. Durante o procedimento de bisseção temporal, os estímulos modelo consistiam em períodos com a luz da caixa acesa (4 e 12 s). Respostas corretas (após o modelo curto, pressionar a barra correlacionada com IP na tarefa de escolha; após o modelo longo, pressionar a barra anteriormente correlacionada com AC nessa mesma tarefa) produziam uma pelota e, em seguida, um IET de $15 \mathrm{~s}$. Respostas incorretas eram seguidas imediatamente pelo IET. Para passar para a fase de teste, os sujeitos tinham que atingir $80 \%$ de acerto com os dois modelos, em cinco sessões consecutivas. Nessa fase, as durações de 4 e 12 s e durações intermediárias $(5,26 ; 6,04 ; 6,93 ; 7,94$ e 9,12 s) foram apresentadas de maneira randômica; nas tentativas com durações intermediárias, não havia liberação de reforço, e nas tentativas com durações de 4 e $12 \mathrm{~s}$, havia liberação do reforço, mas não havia procedimento de correção. Os resultados demonstraram que, na tarefa de escolha, quanto maior o valor do atraso na barra correlacionada com IP, mais frequente a escolha relativa de AC. Em relação à tarefa de bisseção temporal, foi obtida uma curva sigmoide, indicando o desenvolvimento de controle temporal. Foi observada também uma correlação estatisticamente significativa entre as escolhas médias de AC e o desvio padrão do PIS (quando as escolhas de 'longo' são sensíveis à duração dos estímulos modelo, o desvio padrão do PIS varia diretamente com a inclinação da função psicométrica). Os autores concluíram que escolhas de IP podem ser decorrentes de uma pobre discriminação temporal. No entanto, por se tratar de um estudo correlacional, os autores sugerem que outros estudos sejam realizados com o objetivo de verificar se há uma relação causal entre controle temporal e AC. Baumann e Odum (2012) também observaram, com humanos, correlação, embora com valor baixo, entre discriminação temporal (avaliada por meio do procedimento de bissecção) e escolha de AC (analisada a partir do procedimento do 
desconto). Nesse estudo, quanto maior o desconto (i.e, maior a impulsividade) maior a tendência a superestimar a passagem do tempo.

\section{JUSTIFICATIVA E OBJETIVO DO ESTUDO}

Os estudos apresentados acima indicam uma relação entre controle temporal e escolhas de AC (Baumann \& Odum, 2012; Darcheville \& cols., 1992; Marshall \& cols., 2014; Smith \& cols., 2015). No entanto, a metodologia utilizada nesses estudos permitiu apenas a observação de correlações entre essas variáveis, com exceção daquela usada por Smith e cols. Nesse último estudo, foi efetuada uma avaliação da escolha entre IP e AC, a qual foi seguida pelo treino com um esquema de reforçamento e pelo retorno à condição de escolha. Foram utilizados dois esquemas temporais, DRL e FI, cada um com dois valores, os quais eram apresentados sucessivamente. Os resultados sugeriram que o controle temporal, tipicamente observado com a exposição a esses esquemas, favoreceu a escolha de AC, principalmente após o treino com esquemas FI.

Diante desses resultados, o presente estudo objetivou ampliar a investigação do papel do controle temporal sobre a escolha entre IP e AC. Em esquemas DRL e FI, apenas a resposta emitida após o IRI produz o reforço. No esquema DRL, outras respostas não devem ser emitidas durante o IRI e, no esquema FI, outras respostas podem ocorrer durante esse intervalo. Essa distinção levantou uma questão: o que ocorreria com as escolhas de AC caso o esquema exigisse a emissão de respostas durante o IRI (como ocorre com esquemas FR), uma vez que alguns estudos indicam que atividade durante o atraso pode facilitar a escolha de AC (e.g., Darcheville \& cols., 1992; Grosh \& Neuringer, 1981; Mischel \& cols., 1972; Moreira \& Abreu-Rodrigues, 2008). Para responder essa pergunta, um delineamento ABA, similar ao de Smith e cols. (2015), foi utilizado no Experimento 1. Ou seja, após a exposição ao procedimento de Rachlin (A), ratos foram expostos a um 
esquema de reforçamento (B) e, em seguida, retornaram ao procedimento de Rachlin (A). Foram utilizados três esquemas de reforçamento (FR, DRL e FI), com relações respostareforço distintas, mas com IRIs similares e comparáveis ao valor do atraso de AC na linha de base. Diferentemente do estudo de Smith e cols., no qual um delineamento de grupo foi utilizado para avaliar o efeito dos esquemas, no presente estudo todos os sujeitos foram expostos a todos os esquemas, ou seja, foi utilizado um delineamento intrassujeito.

Outra questão investigada se relacionou à discriminação entre as durações dos atrasos de IP e AC. Os resultados obtidos por Marshall e cols. (2014) sugerem que a discriminação temporal, estabelecida por meio do procedimento de bissecção, pode promover a escolha de $\mathrm{AC}$, mas o delineamento experimental usado (AB) por esses autores não permitiu o estabelecimento de relações funcionais entre essas variáveis. Dessa forma, os experimentos 2 e 3 avaliaram o papel do treino de bissecção temporal por meio de um delineamento $\mathrm{ABA}$, que se distinguiu daquele utilizado no Experimento 1 em relação à fase B. Nesses dois últimos experimentos, na fase B, os animais foram expostos a um treino de bissecção, durante o qual os modelos tinham duração idêntica àquelas dos atrasos de IP e de AC. 


\section{EXPERIMENTO 1}

O Experimento 1 teve como objetivo investigar se a exposição a esquemas com relações resposta-reforço distintas, mas com intervalos entre reforços similares, afetaria diferencialmente a escolha por AC.

\section{Método}

\section{Sujeitos}

Oito ratas albinas Wistar, uma experimentalmente ingênua (L22) e sete com experiência em procedimentos de autocontrole e discriminação temporal (L13, L14, L6, L17, L18, L19 e L20) foram utilizadas. A rata L22 iniciou o experimento com aproximadamente cinco meses de idade e as demais sujeitos, com aproximadamente 1 ano de idade. Os sujeitos foram alojados em caixas de polipropileno individuais $(16 \mathrm{~cm} \mathrm{de}$ altura x $39 \mathrm{~cm}$ de comprimento x $32 \mathrm{~cm}$ de profundidade) no biotério do Laboratório de Análise Experimental do Comportamento do Instituto de Psicologia da Universidade de Brasília, instituição na qual foi realizado o estudo. Durante o experimento, os animais foram mantidos à $80 \%( \pm 10 \mathrm{~g})$ de seu peso livre, com acesso livre à água e em um ambiente com um ciclo de $12 \mathrm{~h}$ claro e $12 \mathrm{~h}$ escuro (luzes eram acesas às 6:45 h). As sessões experimentais foram realizadas sete dias por semana e tinham duração aproximada de $1 \mathrm{~h}$.

\section{Equipamento}

Foram utilizadas seis câmaras de condicionamento operante $(21 \mathrm{~cm}$ de altura x 30,5 cm de comprimento x $24 \mathrm{~cm}$ de profundidade) Med Associates®. Cada câmara estava inserida em uma caixa de isolamento acústico e visual. $\mathrm{O}$ teto e as paredes laterais das câmaras eram compostos de material acrílico transparente e os paineis de trabalho e do fundo, de alumínio. O painel de trabalho continha duas barras (barra direita e barra 
esquerda), com $4 \mathrm{~cm}$ de comprimento cada, distantes $12 \mathrm{~cm}$ uma da outra e localizadas a $1,5 \mathrm{~cm}$ de cada parede lateral. No centro do painel do fundo havia uma barra (barra do fundo). Todas as três barras estavam localizadas a $7 \mathrm{~cm}$ do chão e eram operadas por uma força mínima de $0,25 \mathrm{~N}$. Acima de cada barra havia uma lâmpada de $28 \mathrm{~V}$ a $14 \mathrm{~cm}$ do chão (luz da barra esquerda, luz da barra direita e luz da barra do fundo), e acima da lâmpada da barra do fundo, a $18 \mathrm{~cm}$ do chão, havia uma lâmpada adicional (luz da caixa), que ficou acessa durante as sessões experimentais, exceto nos períodos de BO. No painel de trabalho havia um bebedouro, localizado em uma abertura de $5 \mathrm{~cm} \times 5 \mathrm{~cm}$ entre as barras direita e esquerda, e a 1,5 cm do chão, Quando o bebedouro era acionado, uma concha com 0,05 ml de uma mistura de água e leite condensado (50\% vol/vol) era introduzida na abertura por um período de $4 \mathrm{~s}$. Um ventilador, localizado em uma das paredes da caixa de isolamento, produzia um ruído branco durante a sessão experimental. A programação das condições experimentais e o registro dos dados foram realizados por um computador Pentium conectado à cada câmara de condicionamento por meio de um sistema interface Med Associates ${ }^{\circledR}$.

\section{Procedimento}

O experimento foi composto por três fases: (1) Linha de Base IP-AC, (2) Treino com Esquemas e (3) Treino com Esquemas + Teste IP-AC. Os sujeitos foram expostos, três vezes, às fases 1,2 e 3 , nesta ordem. Essas três exposições se diferenciaram em relação ao tipo de esquema de reforçamento em vigor durante o Treino.

Linha de Base IP-AC (LB). Os sujeitos foram expostos a uma situação de escolha entre IP e AC, conforme o procedimento proposto por Rachlin (1974). No início de cada tentativa, as luzes das barras direita e esquerda e a luz da caixa eram acesas, e um esquema concorrente encadeado estava em vigor. Nos elos iniciais operava o esquema conc VI $30 \mathrm{~s}$ VI 30 s, programado de forma dependente nas barras direita e esquerda. Ou seja, o registro 
da passagem do tempo era feito por um único contador e o tipo de elo terminal em cada tentativa era pré-determinado pelo experimentador. Dessa forma, se a programação determinasse que o elo terminal de IP operasse em uma determinada tentativa, a primeira resposta em uma das barras, após a passagem de 30 s, em média, iniciava este elo; se a programação determinasse que fosse o elo terminal de $\mathrm{AC}$, a primeira resposta na outra barra, após transcorridos 30 s, em média, iniciava este elo. Com esse tipo de programação, o número de elos terminais de IP era igual ao número de elos terminais de $\mathrm{AC}$ em cada sessão e, assim, o número de reforços entre os elos terminais era idêntico (Snyderman, 1983). Com o objetivo de evitar o reforçamento acidental de respostas de mudança, foi programado um atraso do reforço para essa resposta (do inglês changeover delay - COD) de $2 \mathrm{~s}$, ou seja, uma resposta em uma barra, após uma resposta na outra barra, só iniciava o elo terminal programado se, além de terem transcorrido $30 \mathrm{~s}$, em média, o tempo entre essas respostas fosse igual ou superior a $2 \mathrm{~s}$. Para alguns sujeitos, as barras direita e esquerda estavam correlacionadas com os elos terminais de IP e de AC, respectivamente, e para outros, o inverso ocorreu.

Durante os elos terminais, as luzes das barras direita e esquerda eram apagadas, enquanto a luz da caixa permanecia acesa. No elo terminal de IP havia um atraso de $2 \mathrm{~s}$ e, em seguida, o bebedouro era acionado uma única vez (reforço imediato e de menor magnitude). Por outro lado, no elo terminal de AC, ocorria um atraso de $18 \mathrm{~s}$, ao final do qual o bebedouro era acionado três vezes (reforço atrasado e de maior magnitude). Em ambos os elos terminais, o bebedouro ficava disponível durante $4 \mathrm{~s}$ cada vez que era acionado. O final da liberação do reforço determinava o início de um período de BO de 31 $\mathrm{s}$ (elo terminal de IP) e $5 \mathrm{~s}$ (elo terminal de AC), durante o qual a luz da caixa era apagada. Ao final do BO, as luzes das barras e a luz da caixa eram acesas, dando início a uma nova tentativa. O BO foi incluído para igualar a duração dos elos terminais. Respostas na barra 
do fundo eram registradas, mas não havia consequência programada para as mesmas nessa fase. A luz da barra do fundo permaneceu apagada durante toda a sessão experimental.

Cada sessão foi composta por 28 tentativas, quatro tentativas forçadas (duas de IP e duas de $\mathrm{AC})$ e 24 tentativas livres (12 de AC e 12 de IP). Tentativas forçadas e livres diferiam apenas em termos da iluminação das barras durante o elo inicial: nas tentativas forçadas, apenas a luz da barra correspondente ao elo terminal pré-programado estava acesa; nas tentativas livres, as luzes das duas barras estavam acesas simultaneamente.

Essa fase era finalizada após, no mínimo, 10 sessões, e quando os seguintes critérios de estabilidade eram atendidos simultaneamente: (1) a escolha relativa do elo terminal de AC (total de respostas na barra correlacionada ao elo terminal de AC dividido pelo total de respostas em ambas as barras) deveria ser igual ou inferior a 40\%; (2) a escolha relativa média de $\mathrm{AC}$ nas três últimas sessões e nas três penúltimas sessões não podia diferir em mais que $10 \%$; e (3) não podia haver tendência crescente ou decrescente na escolha relativa de $\mathrm{AC}$ nas seis últimas sessões. Para os sujeitos que apresentaram escolhas relativas de AC superiores a 0,4, houve um aumento do atraso nesse elo de 18 para $30 \mathrm{~s}$ (o valor do BO no elo terminal de IP também foi ajustado de modo a igualar a duração dos dois tipos de elo). Quando a escolha relativa de AC foi igual ou inferior a 0,4 por duas sessões consecutivas, as durações do atraso de $\mathrm{AC}$ e do $\mathrm{BO}$ de IP foram diminuídos gradualmente até atingirem os valores de 18 e 31 s, respectivamente. Para o sujeito L16, tais valores (18 e $31 \mathrm{~s}$ ) foram utilizados apenas na primeira exposição a essa fase; nas demais exposições, o critério de estabilidade foi atingido com o atraso de AC de $20 \mathrm{~s}$ e o BO de IP de $33 \mathrm{~s}$, os mesmos valores utilizados para o sujeito L17 em todas as exposições à LB.

Respostas nas barras direita e esquerda durante o atraso e BO, e respostas na barra do fundo durante toda a fase foram registradas (exceto durante as tentativas forçadas), mas 
não produziram consequências. As sessões eram encerradas após $1 \mathrm{~h}$ ou quando todas as tentativas eram completadas.

Treino com Esquemas (TR). Os sujeitos foram expostos a três esquemas de reforçamento: FR, DRL e FI. Para todos os esquemas, a sessão era iniciada com as luzes da barra do fundo e da caixa acesas. Quando o esquema FR estava em vigor, a emissão de um número fixo de respostas na barra do fundo produzia o reforço. Durante o DRL, o reforço era contingente à primeira resposta na barra do fundo emitida após um determinado período de tempo contado a partir do início da sessão, do término do reforço ou da emissão de uma resposta nessa barra; a emissão de uma resposta durante esse período reiniciava o contador de tempo. Finalmente, com o esquema FI, a primeira resposta na barra do fundo, emitida após um intervalo fixo de tempo, ocasionava a liberação do reforço. A ordem de exposição aos esquemas variou entre sujeitos. Durante a liberação do reforço, disponível por $3 \mathrm{~s}$ em todos os três esquemas, a luz da barra do fundo era apagada e, ao final do reforço, era reacendida. Respostas nas barras direita e esquerda não foram registradas.

Durante o treino com o esquema FI, o valor do intervalo entre reforços (do inglês inter-reinforcement interval - IRI) programado foi sempre igual ao atraso do reforço no elo terminal AC da fase LB anterior. Ou seja, foi usado o esquema FI 18 s para todos os sujeitos, com exceção do sujeito L17, para o qual foi usado o esquema FI 20 s. Durante o treino com os esquemas FR e DRL, entretanto, os valores desses esquemas foram modificados ao longo das sessões. Essas modificações visavam tornar o IRI médio nesses esquemas similar ao atraso do reforço no elo terminal de $\mathrm{AC}$ da fase LB imediatamente anterior. Dessa forma, os valores dos esquemas FR e DRL utilizados geraram IRIs médios próximos a 20 s para os sujeitos L16 e L17, e próximos a $18 \mathrm{~s}$ para os demais sujeitos. Os seguintes critérios foram adotados para o ajuste dos valores dos esquemas FR e DRL. Primeiro, se o IRI médio, calculado diariamente, fosse inferior a $18 \mathrm{~s}$ (ou $20 \mathrm{~s}$ ), havia o 
aumento de uma unidade nos valores desses esquemas (e.g., de FR 4 para FR 5, de DRL 4 s para DRL $5 \mathrm{~s}$ ); por outro lado, se o IRI médio fosse superior a $18 \mathrm{~s}$ (ou $20 \mathrm{~s}$ ), uma unidade era subtraída dos valores dos esquemas. Segundo, o valor dos esquemas FR ou DRL só era aumentado quando, no mínimo, $80 \%$ dos reforços programados fossem obtidos na sessão.

As sessões terminavam após 45 reforços ou 40 min. Para a finalização dessa fase (TRFR, TRDRL ou TRFI) era necessário que os seguintes critérios fossem atendidos simultaneamente: (1) mínimo de 15 sessões, (2) IRI médio igual ou superior a 16 s nas quatro sessões consecutivas (18 s para os sujeitos L17 e L16 nos esquemas anteriormente indicados), e (3) média do IRIs das últimas quatro sessões igual ou superior a $80 \%$ do valor do atraso de AC na fase LB imediatamente anterior. Devido a um erro do experimentador, o sujeito L17 permaneceu na fase TRFR por apenas 12 sessões (ao invés de 15).

Treino com Esquemas + Teste IP-AC $(\boldsymbol{T R}+\boldsymbol{T T})$. A fase $\mathrm{TR}+\mathrm{TT}$ esteve em vigor por 10 sessões e cada sessão dessa fase era composta por duas partes. Na primeira, o sujeito era exposto a um esquema idêntico àquele que estava em vigor na fase anterior (FR, DRL ou FI) até a obtenção de 30 reforços ou até a passagem de 20 min. Na segunda, foram implementadas tentativas de escolha entre $\mathrm{IP}$ e $\mathrm{AC}$, idênticas às da fase $\mathrm{LB}$ correspondente, até a ocorrência de 16 tentativas, quatro forçadas (duas de IP e duas de AC) e 12 livres (seis de IP e seis de AC), ou até a passagem de 40 min.

\section{Resultados e Discussão}

O delineamento experimental previa que todos os sujeitos fossem expostos três vezes às fases $\mathrm{LB}$, TR e TR+TT, sendo cada exposição correspondente a um dos três esquemas de reforçamento (FR, DRL e FI). Isso ocorreu para todos os sujeitos, com exceção do sujeito L16. Devido ao término do prazo para coleta de dados, esse sujeito não 
passou pela sequência de fases com o esquema DRL. Além disso, na fase TRFI+TT, o sujeito L13 foi exposto a oito sessões e o sujeito L16 a nove sessões, em vez de 10, devido a uma falha do experimentador.

A Figura 1 mostra, para cada sujeito, a escolha relativa de AC nas seis últimas sessões de cada ocorrência da fase LB (cada uma delas anterior a um esquema específico). Essa medida foi obtida dividindo-se o número de respostas emitidas na barra esquerda (correlacionada com AC), pelo número total de respostas nas barras direita (correlacionada com IP) e esquerda, durante os elos iniciais. Valores iguais a 0,5 indicam que o número de escolhas foi igual entre as alternativas de IP e de AC, valores abaixo de 0,5 mostram um número maior de escolhas de IP, enquanto que valores acima de 0,5 mostram um número maior de escolhas de AC. As colunas da esquerda, do centro e da direita referem-se às fases LB imediatamente anterior aos esquemas FR, DRL e FI, respectivamente. Os números à esquerda cada painel referem-se à ordem de exposição a cada esquema.

\section{Linha de Base IP-AC}

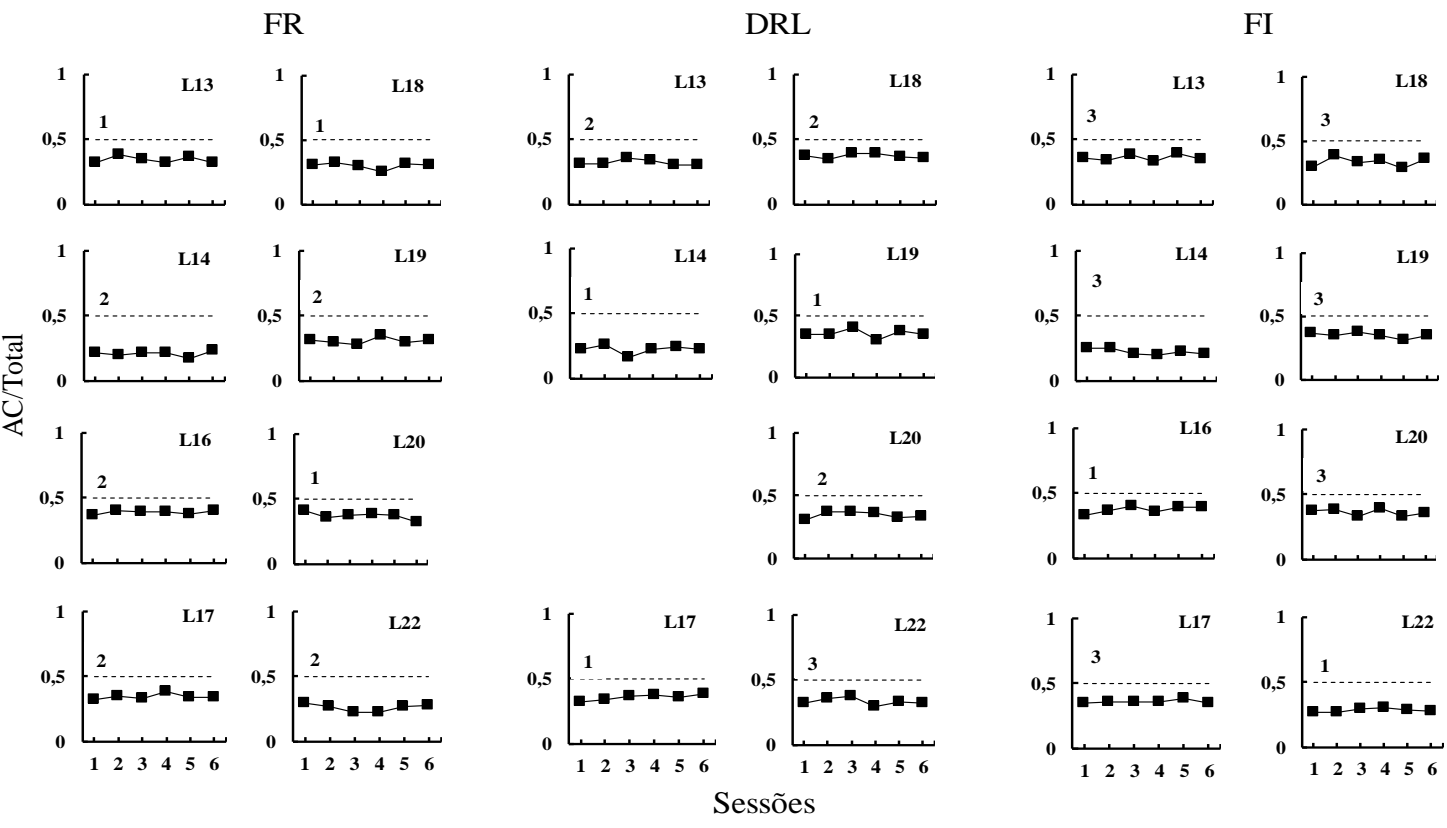

Figura 1. Escolha relativa de AC nas seis últimas sessões da fase LB imediatamente anterior ao treino com os esquemas FR, DRL e FI, para cada sujeito no Experimento 1. Os números 1, 2 e 3 indicam a ordem de exposição aos esquemas. 
Durante as três exposições a essa fase, os sujeitos apresentaram escolhas relativas de $\mathrm{AC}$ iguais ou inferiores a 0,4, como exigido pelo critério de estabilidade. Ou seja, os sujeitos escolheram a alternativa de IP na maioria das tentativas, um resultado comumente observado quando reforços primários (e prontamente consumidos) são utilizados, o que é mais usual em estudos com animais não humanos ou com crianças (e.g., Ainslie, 1975; Green \& Estle, 2003; Hackenberg \& Vaidya 2003; Marshall \& cols., 2014; Navarick, 1998; Rachlin \& Green, 1972).

Os resultados obtidos durante a exposição aos esquemas FR (fases TRFR e TRFR+TT), DRL (fases TRDRL e TRDRL+TT) e FI (fases TRFI e TRFI+TT) são apresentados nas tabelas 1 e 2 . A Tabela 1 indica o valor do esquema, a média dos IRIs (soma dos IRIs dividida pelo número de reforços) e a média das taxas de respostas (número de respostas na barra do fundo dividido pela duração total da sessão), assim como os respectivos desvios padrão, nas quatro últimas sessões de cada fase TR e em todas as sessões de cada fase TR+TT. Devido a uma falha na programação, não foram calculados: a taxa de respostas para os sujeitos L16 e L22, na fase TRFI, e para o sujeito L20, o IRI médio na primeira sessão da fase TRFR+TT e a taxa de respostas nas duas primeiras sessões da mesma fase. Além disso, em duas sessões, os valores do IRI médio foram inferiores a 18 e 16 s para os sujeitos L16 e L20, respectivamente.

Em concordância com os critérios de estabilidade em vigor nas três ocorrências da fase TR, a Tabela 1 indica que, para a maioria dos sujeitos, os valores dos IRIs obtidos em cada exposição às fases TRFR, TRDRL e TRFI foram similares ou acima dos valores do atraso de AC na fase LB anterior (conforme descrito na seção de Método, esse atraso era 18 s para todos os sujeitos ao longo do Experimento 1, com exceção dos sujeitos L16, nas fases TRFR e TRDRL, e L17, nas três ocorrências da fase TR, para os quais o atraso era 20 s). Nas três ocorrências da fase TR+TT, embora a mudança do esquema (TR) para a 
contingência de escolha (TT) fosse efetuada após 30 reforços, de modo que não havia nenhuma exigência relacionada ao IRI obtido, também foram observados valores de IRI similares ou acima dos valores esperados, com exceção dos sujeitos L16 e L20, na fase TRFR+TT, os quais mostraram IRIs iguais a 15,7 e 16,9 s, respectivamente (os valores esperados para eles eram 20 e $18 \mathrm{~s}$, respectivamente).

Tabela 1

Valor (V) do esquema, média (M) do IRI e da taxa de respostas (TxR), e desvio padrão (DP) nas quatro últimas sessões da fase TR e em todas as sessões da fase TR+TT, para cada sujeito no Experimento 1.

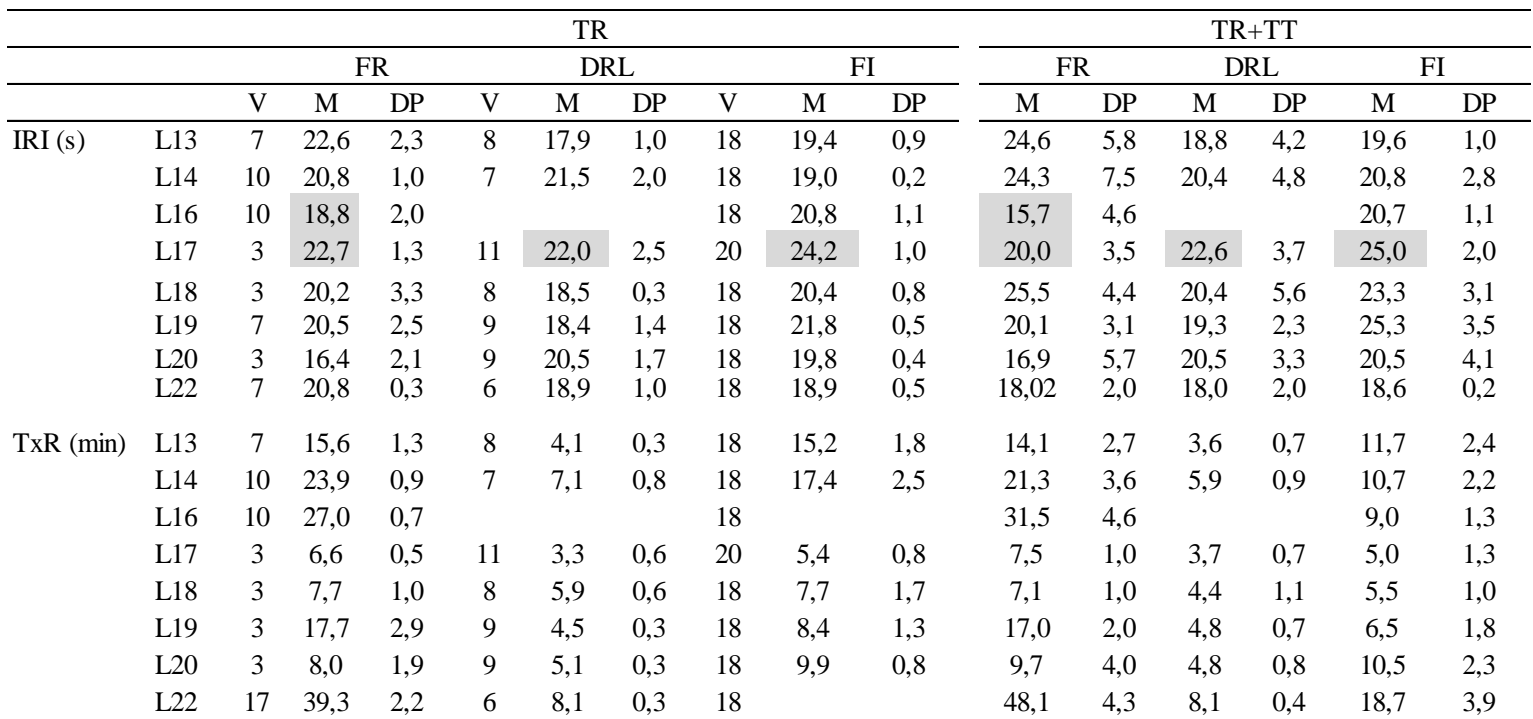

Nota: valores marcados com a cor cinza representam os esquemas em que o valor do IRI médio esperado era de $20 \mathrm{~s}$.

Para a maioria dos sujeitos, as taxas de respostas por min durante a exposição ao esquema na fase TR não se alteraram quando o mesmo esquema estava em vigor na fase TR+TT (ver Tabela 1). Os sujeitos expostos aos maiores valores (10 e 17) do esquema FR apresentaram taxas de respostas mais altas (entre 23,9 e 39,3 na fase TR e entre 21,3 e 48,1 na fase TR+TT) do que aqueles expostos aos menores valores ( 3 e 7) desse esquema (entre 6,6 e 17,7 na fase TR e entre 7,5 e 17,0 na fase TR+TT). No esquema DRL, as menores taxas de respostas (3,3 na fase TR e 3,7 na fase TR+TT) foram obtidas com o maior valor do esquema (DRL 11 s). No esquema FI, o sujeito L22 (o único que era experimentalmente 
ingênuo quando exposto a esse esquema) apresentou taxas de respostas mais altas do que os demais sujeitos. Ao longo das fases, para todos os animais, as taxas de respostas foram mais altas no esquema FR (18,9 respostas por min, em média), intermediárias no esquema FI (10,1 respostas por min, em média) e mais baixas no esquema DRL (5,2 respostas por min, em média), um resultado consistente com aqueles da literatura (e.g., Cole, 2011; Ferster \& Skinner, 1957; Porto, Ramos \& Costa, 2011; Weiner, 1969).

No entanto, as taxas de respostas obtidas nos esquemas FR e FI foram mais baixas do que aquelas comumente relatadas na literatura. Por exemplo, Cole (2011) encontrou taxas próximas a 90 respostas por min ao expor ratos ao esquema FR 20 e próximas a 15 respostas por min ao expor os sujeitos ao esquema FI 20 s. LeFrancois e Metzger (1993), por sua vez, encontraram taxas em torno de 60 respostas por min com o esquema FR 30 e em torno de 30 respostas por min com o esquema FI 42 s. É possível que taxas de respostas mais baixas tenham sido obtidas no presente estudo porque responder na barra situada na parede oposta à parede do bebedouro implicava maior deslocamento entre barra e bebedouro e, portanto, respostas nessa barra tinham maior custo do que respostas na barra situada ao lado do bebedouro (esta era a localização da barra nos estudos de Cole e LeFrancois \& Metzger). O efeito do custo da resposta sobre a taxa de respostas foi demonstrado por Alling e Poling (1995). Nesse estudo, ratos foram expostos a um esquema múltiplo FR FR em que o custo da resposta (força necessária para pressionar a barra e, assim, produzir o reforço) foi manipulado. Aumentar o custo da resposta diminuiu a taxa de respostas média (ver também Chung, 1965; Miller, 1970).

A Tabela 2 apresenta a pausa pós-reforço média durante o esquema FI (quatro últimas sessões da fase TRFI e todas as sessões da fase TRFI+TT), para cada sujeito. Essa medida foi calculada dividindo-se a soma do tempo entre o início de cada intervalo e a emissão da primeira resposta pelo número de reforços obtidos na sessão. Se forem 
considerados todos os sujeitos conjuntamente, observa-se que a duração da pausa não diferiu entre as fases: na fase TRFI, em que foi usado o esquema FI $18 \mathrm{~s}$ (exceto para o sujeito L17), a pausa variou entre 6,7 e 19,2 s, e na fase TRFI+TT, entre 6,5 e 25,8 s. Para o sujeito L17, exposto ao esquema FI 20 s, a duração da pausa variou entre 19,6 e 23,2 s na fase TRFI, e entre 19,6 e 25,8 s na fase TRFI+TT.

Tabela 2

Pausa pós-reforço média durante o esquema FI nas quatro últimas sessões da fase TRFI e em todas as sessões da fase TRFI+TT, para cada sujeito no Experimento 1.

\begin{tabular}{ccccccccc}
\hline & L13 & L14 & L16 & L17 & L18 & L19 & L20 & L22 \\
\hline TRFI & 16,4 & 11,6 & 10,8 & 23,2 & 15,9 & 19,2 & 11,9 & 7,5 \\
& 12,3 & 11,7 & 11,6 & 22,3 & 18,2 & 15,3 & 12,8 & 7,6 \\
& 13,6 & 13,0 & 9,4 & 19,6 & 17,0 & 17,4 & 11,0 & 7,0 \\
\multirow{5}{*}{ Média } & 13,4 & 13,2 & 14,2 & 22,2 & 15,2 & 16,8 & 11,0 & 9,0 \\
TRFI+TT & 13,9 & 12,4 & 11,5 & 21,8 & 16,6 & 17,2 & 11,7 & 7,8 \\
& 16,3 & 15,8 & 15,6 & 19,6 & 16,1 & 28,3 & 9,5 & 10,1 \\
& 12,9 & 15,8 & 13,1 & 21,3 & 17,4 & 18,1 & 10,8 & 8,5 \\
& 15,4 & 13,5 & 11,1 & 20,9 & 17,4 & 18,2 & 8,8 & 7,7 \\
& 15,2 & 13,6 & 12,9 & 25,8 & 16,4 & 19,3 & 12,0 & 8,1 \\
& 12,6 & 13,4 & 14,4 & 21,0 & 25,7 & 20,2 & 10,7 & 6,5 \\
& 12,4 & 17,9 & 12,2 & 24,2 & 18,7 & 22,2 & 12,2 & 11,9 \\
& 13,0 & 14,0 & 12,2 & 21,2 & 25,8 & 16,8 & 11,6 & 11,4 \\
& 12,73 & 16,0 & 15,5 & 22,3 & 18,8 & 15,7 & 11,7 & 10,4 \\
& & 13,4 & 14,0 & 22,1 & 15,8 & 17,9 & 20,3 & 8,6 \\
& & 14,7 & & 25,7 & 20,7 & 22,3 & 14,0 & \\
\hline \multirow{6}{*}{ Média } & 13,8 & 14,8 & 13,4 & 22,4 & 19,3 & 19,9 & 12,2 & 9,2 \\
\hline
\end{tabular}

A literatura aponta que o tamanho da pausa tende a variar entre $1 / 3$ e $2 / 3$ do tamanho do IRI (Dukich \& Lee, 1973; Schneider, 1969). No presente experimento, 1/3 e $2 / 3$ de 18 s correspondem a 6 e 12 s, enquanto que $1 / 3$ e $2 / 3$ de 20 s (sujeito L17) correspondem a 6,7 e 13,3 s, respectivamente. Como mostrado na Tabela 2, na maioria das quatro sessões finais da fase TRFI, para quatro sujeitos (L13, L14, L16 e L20), o valor da pausa foi próximo a 2/3 do valor do IRI, e para três sujeitos (L17, L18 e L19), o valor da pausa foi próximo ou acima do valor do IRI; na fase TRFI+TT, as pausas tenderam a ser mais longas do que aquelas observadas no TRFI. Para o sujeito L22, em ambas as fases, a 
pausa foi menor do que $2 / 3$ do valor do IRI na maioria das sessões. A ocorrência de pausas longas para todos os sujeitos indica que o desempenho no esquema FI foi mais próximo daquele obtido no esquema DRL do que no esquema FR.

Em conjunto, as tabelas 1 e 2 indicam que: (1) os IRIs médios foram comparáveis (e similares ou superiores ao atraso de AC) entre os esquemas FR, DRL e FI, os quais envolviam relações resposta-reforço distintas; (2) o esquema FR produziu taxas de respostas mais altas do que o esquema DRL, enquanto o esquema FI produziu taxas de respostas intermediárias; (3) em todas as sessões das fases com esquema FI, os sujeitos passaram pelo menos $50 \%$ da duração do intervalo sem emitir a resposta de pressionar a barra do fundo (com exceção do sujeito L22); e (4) em conformidade com o que ocorreu com as taxas de respostas, a pausa pós-reforço média durante o esquema FI foi menor do que as pausas (pós-reforço ou entre respostas, isto é, o IRI médio) obtidas no esquema DRL. Uma vez que o IRI médio foi similar entre os esquemas, essas diferenças entre as taxas de respostas e as pausas pós-reforço nos três esquemas seriam esperadas. Isso porque, no esquema FR, quanto mais rapidamente o sujeito responder, mais rapidamente receberá o reforço (pausas implicam atrasos na liberação do reforço). No esquema FI, o reforço é contingente à emissão de uma única resposta após a passagem de um determinado período de tempo, podendo ou não haver respostas nesse período, de modo que as taxas tendem a ser mais baixas do que no esquema FR. E no esquema DRL, uma vez que o reforço é baseado no espaçamento temporal entre as respostas, taxas de respostas mais baixas do que nos dois esquemas anteriores tendem a ocorrer (Catania, 1991, 1999).

A Figura 2 mostra a escolha relativa de AC na fase TR+TT como uma proporção da escolha relativa de AC na fase LB. Essa medida foi calculada dividindo-se a escolha relativa de AC em cada sessão da fase TR+TT pela média da escolha relativa de AC nas seis últimas sessões da fase LB. Valores iguais a 1,0 indicam que a escolha relativa de AC 
foi igual nas duas fases e valores abaixo e acima de 1,0 indicam que houve diminuição e aumento, respectivamente, na escolha relativa de AC na fase TR+TT quando comparada com a fase LB correspondente. As colunas da esquerda, do centro e da direita referem-se ao esquema de reforçamento em vigor na fase TR (FR, DRL e FI, respectivamente).

\section{Teste IP-AC}
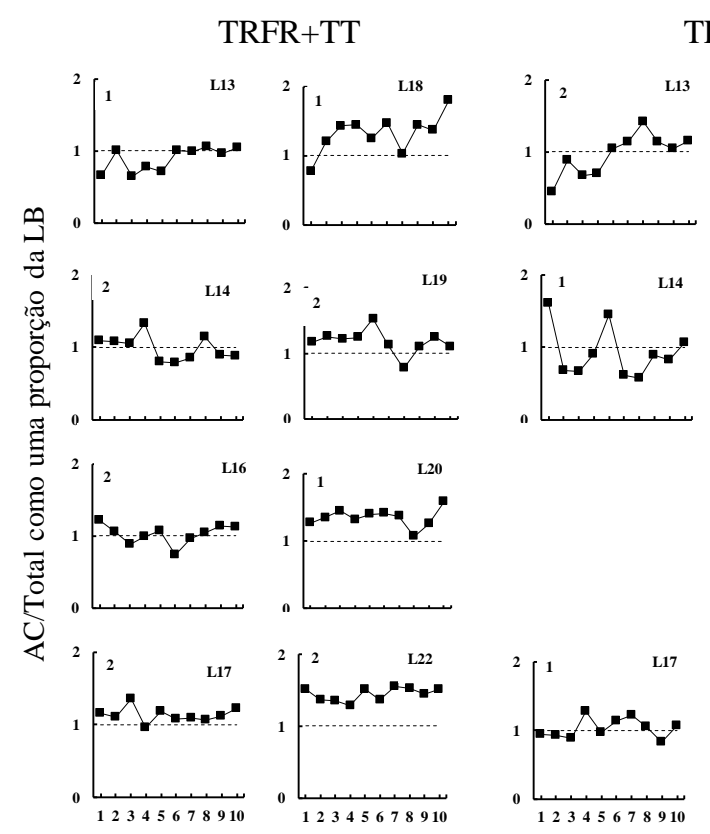

TRDRL+TT

TRFI+TT
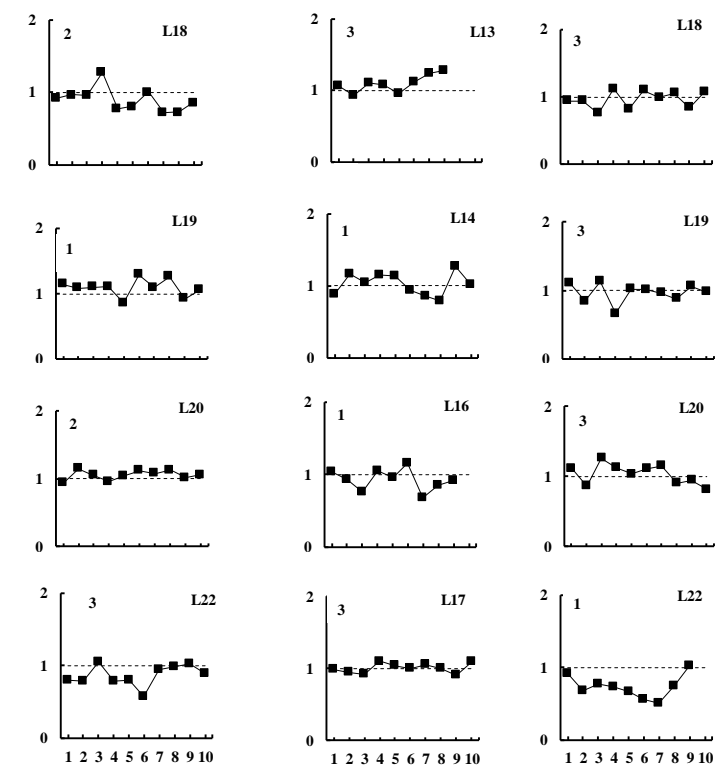

Sessões

Figura 2. Escolha relativa de $\mathrm{AC}$ em todas as sessões da fase $\mathrm{TR}+\mathrm{TT}$ como uma proporção das escolhas relativas de AC na fase LB imediatamente anterior, para cada sujeito no Experimento 1. Os números 1,2 e 3 indicam a ordem de exposição aos esquemas.

Após o treino com o esquema FR (fase TRFR+TT) houve um aumento nas escolhas de AC para a maioria dos sujeitos (as exceções ocorreram com os sujeitos L13 e L14). Entretanto, após o treino com os esquemas DRL (fase TRDRL+TT) e FI (fase TRFI+TT), as escolhas de AC permaneceram próximas àquelas observadas na fase LB para a maioria dos sujeitos (exceções ocorreram, por exemplo, para os sujeitos L13 e L14 após o esquema DRL, e para os sujeitos L13 e L22 após o esquema FI). 
A Figura 3 apresenta uma análise complementar da escolha relativa de AC nas fases TR+TT como uma proporção da escolha relativa de AC na fase LB correspondente. Para efetuar essa análise, a proporção da escolha relativa de AC em cada sessão da fase TR+TT, após o treino com determinado esquema, foi subtraída da proporção da escolha relativa de AC na sessão correspondente da fase TR+TT que seguiu o treino com outro esquema. Três diferenças são mostradas: FR-DRL (paineis da esquerda), FR-FI (paineis do centro) e FI-DRL (paineis da direita). Por exemplo, se a proporção de escolha no esquema DRL for subtraída da proporção de escolha no esquema FR (FR-DRL), uma diferença igual a 0 indica que a mudança na escolha de AC após o treino com esses esquemas foi igual; valores acima e abaixo de 0 indicam que a mudança na escolha de $\mathrm{AC}$ foi maior no esquema FR e DRL, respectivamente.

$\mathrm{O}$ aumento da escolha relativa de AC foi maior após a exposição ao esquema FR, quando comparado aos esquemas DRL (com exceção do sujeito L13) e FI (com exceção dos sujeitos L13 e L14). Por outro lado, a comparação das escolhas relativas de AC após os treinos com os esquemas DRL e FI mostra que o aumento nessas escolhas tendeu a ser maior após o esquema FI para o sujeito L14 e após o esquema DRL para o sujeito L22; para os demais sujeitos, os resultados variaram ao longo das sessões.

Em suma, os resultados das figuras 2 e 3 sugerem que, embora os sujeitos tenham sido expostos a IRIs similares entre os esquemas (e comparáveis ao valor do atraso de AC), os efeitos dessa exposição sobre a escolha de AC diferiu entre os esquemas. Ou seja, a exposição ao esquema FR promoveu o aumento da escolha relativa de AC, mas o mesmo não foi sistematicamente observado após o treino com os esquemas DRL e FI. Esses resultados foram independentes da ordem de exposição aos esquemas. 
Teste IP-AC

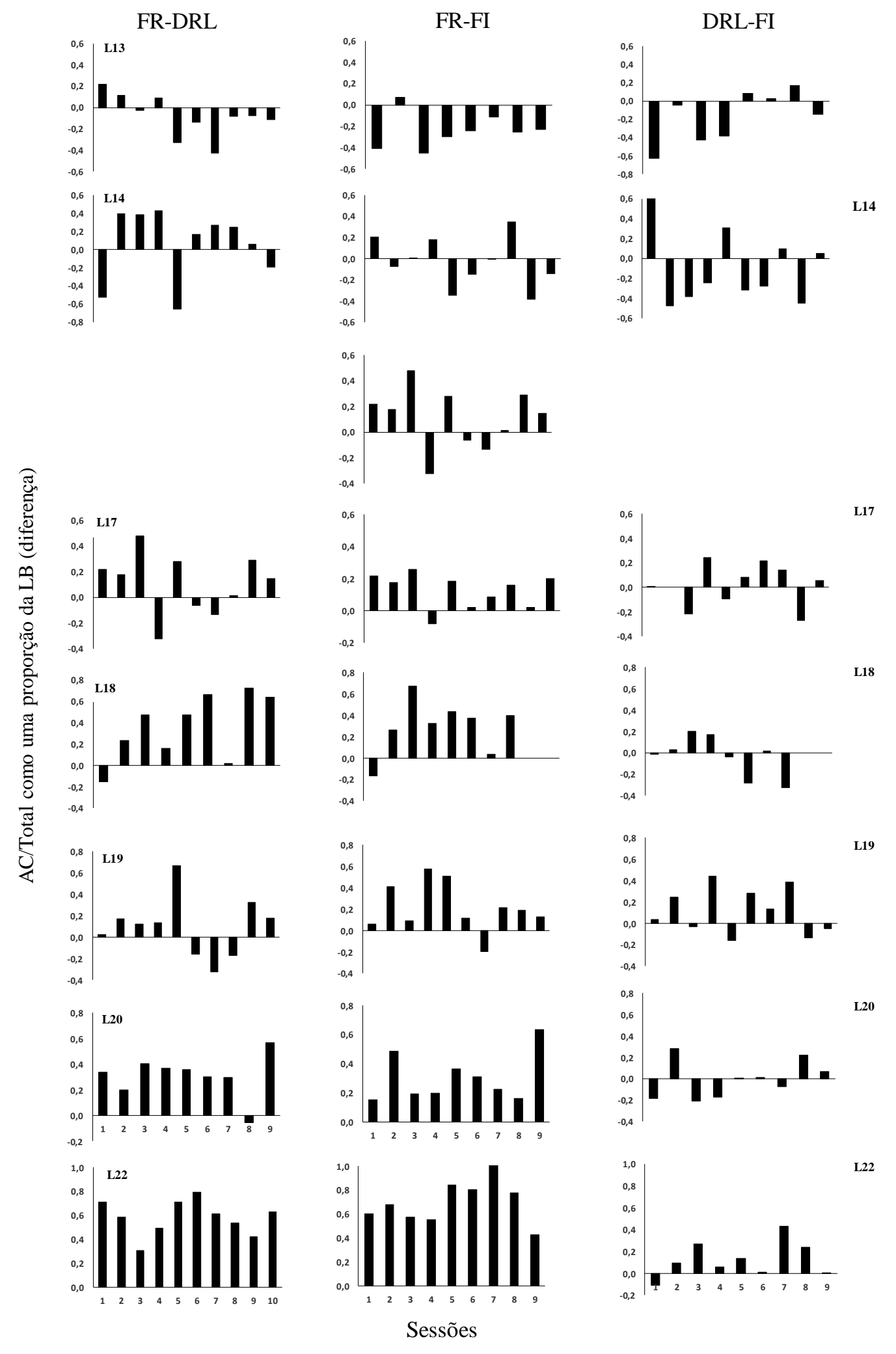

Figura 3. Diferença entre a proporção de escolhas relativas de AC após a exposição aos esquemas FR e DRL, FR e FI, e DRL e FI, em todas as sessões da fase TR+TT, para cada sujeito no Experimento 1 (a escala do eixo Y difere entre sujeitos). 
Os efeitos diferenciais dos esquemas sobre a escolha de $\mathrm{AC}$ sugerem que a exigência de respostas durante o IRI (esquema FR), o qual tinha uma duração próxima à duração do atraso de AC, favoreceu o desenvolvimento de autocontrole. Esses resultados são consistentes com os relatos encontrados na literatura, os quais indicam aumentos nas escolhas relativas de $\mathrm{AC}$ quando os organismos realizam alguma atividade durante o período de espera do reforço (e.g., Darcheville \& cols., 1992; Grosh \& Neuringer, 1981; Mischel \& cols., 1972; Moreira \& Abreu-Rodrigues, 2008), e também com as sugestões de que isso ocorre porque o responder diminui a aversividade da espera pelo reforço (e.g., Galtress \& cols., 2012; Grosh \& Neuringer, 1981; Marshall \& cols., 2014; Mischel \& cols., 1972; Sonunga-Barke, Taylor, Sembi \& Smith, 1992). Esse ponto será retomado na seção de Discussão Geral.

\section{EXPERIMENTO 2}

O Experimento 1 avaliou o papel do controle temporal em situações de escolha entre IP e AC por meio do treino com esquemas de reforçamento. O Experimento 2 ampliou essa investigação substituindo os esquemas de reforçamento pelo procedimento de bissecção. Mais especificamente, o presente experimento verificou se a discriminação dos valores dos atrasos dos elos terminais de IP e AC afetaria diferencialmente a escolha de AC.

\section{Método}

\section{Sujeitos}

Foram utilizadas quatro ratas albinas Wistar, experimentalmente ingênuas (L13, L14, L15 e L16), com cerca de cinco meses de idade no início do experimento. As demais características foram idênticas àquelas descritas no Experimento 1. 


\section{Equipamento}

Similar ao Experimento 1, exceto que as câmaras de condicionamento operante não eram equipadas com a barra do fundo, apenas com as barras direita e esquerda.

\section{Procedimento}

O experimento foi composto por quatro fases: (1) Linha de Base IP-AC, (2) Treino de Bissecção, (3) Treino de Bissecção + Teste de Bissecção e (4) Teste IP-AC.

Linha de Base IP-AC (LB). Similar ao Experimento 1, exceto que inicialmente foi programado um atraso de AC de $12 \mathrm{~s}$ (e um BO de IP de $25 \mathrm{~s}$ ) para todos os sujeitos, mas apenas o sujeito L13 atingiu o critério de estabilidade sob esses valores. Os demais sujeitos atingiram o critério de estabilidade com o atraso de AC igual a 18 s (31 s para o BO de IP).

Treino de Bissecção (TRBI). Nessa fase foi utilizado um procedimento de escolha de acordo com o modelo. A sessão era iniciada com a apresentação de um BO (todas as luzes apagadas) de 2 ou $18 \mathrm{~s}$ - estímulos modelo 'curto' e 'longo', respectivamente (2 ou $12 \mathrm{~s}$ para o sujeito L13). Esses valores foram escolhidos porque correspondiam aos atrasos dos elos terminais IP e AC, respectivamente, na fase LB anterior. Após o final do BO, as luzes das barras direita e esquerda (estímulos de comparação) e a luz da caixa eram acesas. A resposta correta, após o modelo 'curto', consistia em pressionar a barra direita (correlacionada com o elo terminal IP na fase LB), e após o modelo 'longo', em pressionar a barra esquerda (correlacionada com o elo terminal AC na fase LB). A emissão dessa resposta apagava as luzes das barras (a luz da caixa permanecia acesa), acionava o bebedouro por $3 \mathrm{~s}$ e, ao final da apresentação do reforço, iniciava um IET de $20 \mathrm{~s}$. Respostas incorretas (pressionar as barras esquerda e direita após os modelos 'curto' e 'longo', respectivamente) apagava as luzes das barras e produzia apenas o IET. Após o IET, a luz da caixa era apagada e uma nova tentativa era iniciada. 
Quando uma resposta incorreta ocorria em uma tentativa, um procedimento de correção era utilizado. Ou seja, a tentativa era repetida até que a resposta correta fosse emitida. As tentativas de correção foram registradas, mas não foram incluídas na análise de dados.

O critério para finalização dessa fase estabelecia que os sujeitos fossem expostos a, no mínimo, 15 sessões e que a porcentagem de acertos para cada modelo fosse igual ou superior a $80 \%$ em, pelo menos, cinco sessões consecutivas. As sessões eram encerradas após 1 h e 30 min ou após 90 tentativas (o que ocorresse primeiro), 45 com o modelo 'curto' e 45 com o modelo 'longo'. As tentativas eram apresentadas semirrandomicamente, de modo que cada modelo era apresentado não mais do que duas vezes consecutivas.

Treino de Bissecção (TRBI) + Teste de Bissecção (TTBI). Nessa fase, a sessão tinha duas partes. Na primeira parte (TRBI) havia 10 tentativas (cinco com o modelo 'curto' e cinco com o modelo 'longo'), programadas conforme a descrição da fase imediatamente anterior (TRBI). A segunda parte (TTBI) incluía 80 tentativas adicionais: 20 com o modelo 'curto', 20 com o modelo 'longo' e 40 com estímulos de valores intermediários (4, 6, 8 e $10 \mathrm{~s}$ para o sujeito L13; 5, 8, 11 e $14 \mathrm{~s}$ para os demais sujeitos), sendo 10 tentativas com cada valor. Essas 80 tentativas de TTBI foram divididas em 10 blocos de oito tentativas. Cada bloco continha duas tentativas com o modelo 'curto', duas tentativas com o modelo 'longo' e uma tentativa com cada modelo de valor intermediário, apresentadas semirrandomicamente. As tentativas com os modelos de valores intermediários diferiam das tentativas com os modelos 'curto' e 'longo' no que se refere às consequências das respostas nas barras direita ou esquerda. Para os modelos longo e curto, essas respostas produziam consequências idênticas àquelas programadas no TRBI; para os modelos intermediários, essas respostas também apagavam as luzes das barras, mas como não havia liberação do reforço, o IET de 20 s era imediatamente iniciado. 
Cada sessão era encerrada após 1 h 30 min ou após 90 tentativas. Caso a porcentagem de acertos para os modelos 'curto' e 'longo' fosse inferior a 70\% (cf. Machado \& Castro, 2012) em duas sessões consecutivas, o sujeito retornava para a fase TRBI anterior, em que eram apresentados apenas os estímulos modelo 'curto' e 'longo', até que a porcentagem de acerto fosse novamente igual ou superior a $80 \%$ em duas sessões consecutivas. Quando o critério de $80 \%$ de acertos era atingido, o sujeito era novamente exposto à fase TRBI+TTBI até completar cinco sessões consecutivas com, pelo menos, $70 \%$ de acertos. Porcentagem de acertos abaixo de 70\% (64\%) ocorreu apenas para o sujeito L16 e em um único dia de teste. Desse modo, todos os sujeitos foram expostos a cinco sessões consecutivas na fase TRBI+TTBI.

Após completarem a fase TRBI+TTBI, os sujeitos retornaram à fase TRBI por duas sessões e, em seguida, foram expostos ao TT, descrito a seguir.

Teste IP-AC (TT). Similar à LB deste experimento, exceto que, para o sujeito L13, o valor do atraso de AC foi de $12 \mathrm{~s}$ e do BO de IP foi de $31 \mathrm{~s}$.

\section{Resultados e Discussão}

A Figura 4 mostra a escolha relativa de AC nas seis últimas sessões da fase LB,

\section{Linha de Base IP-AC}

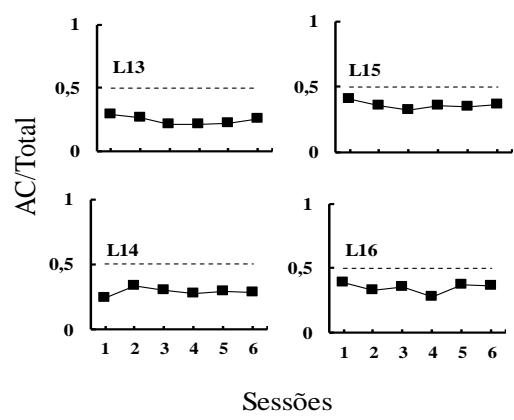

Figura 4. Escolha relativa de AC nas seis últimas sessões da fase LB, para cada sujeito no Experimento 2. 
para cada sujeito. Como exigido pelo critério de estabilidade, todos os sujeitos escolheram o elo terminal de $\mathrm{AC}$ em não mais do que $40 \%$ das tentativas.

Os resultados do treino e do teste de bissecção são apresentados nas figuras 5 e 6 . A Figura 5 mostra a porcentagem de acertos para os modelos 'curto' e 'longo', nas cinco últimas sessões das fases TRBI e TRBI+TTBI. Na fase TRBI, a porcentagem de acertos foi calculada dividindo-se o número de acertos para o modelo 'curto' ('longo') pelo total de ocorrências desse modelo. Na fase TRBI+TTBI, foram incluídas as porcentagens de acertos tanto das 10 primeiras tentativas com os modelos 'curto' e 'longo', idênticas àquelas da fase TRBI anterior, quanto das 80 tentativas em que esses modelos foram apresentados juntamente com os modelos de valores intermediários (o mesmo critério foi adotado no Experimento 3).

\section{Treino e Teste de Bissecção}

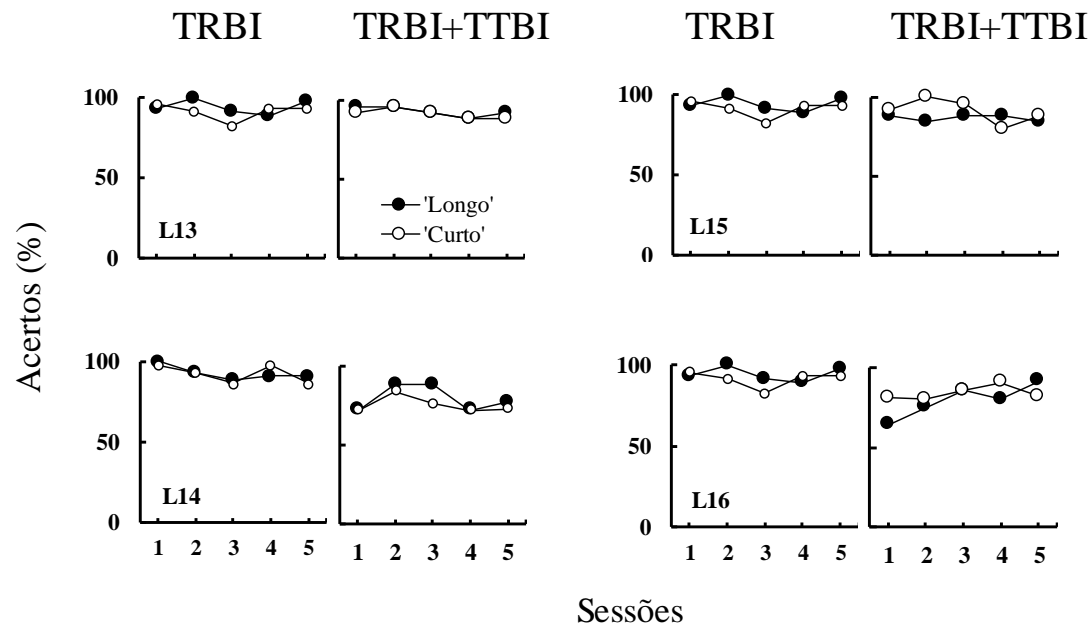

Figura 5. Porcentagem de acertos para os modelos 'curto' e 'longo' nas cinco últimas sessões das fases TRBI e TRBI+TTBI, para cada sujeito no Experimento 2. Círculos vazios representam o modelo 'curto' e círculos cheios representam o modelo 'longo'.

$\mathrm{Na}$ fase TRBI, a porcentagem de acertos foi igual ou superior a $80 \%$ para os dois modelos, conforme estabelecido pelo critério de aprendizagem. Na fase TRBI+TTBI, em 
que não havia critério de aprendizagem, a porcentagem de acertos se manteve próxima a $80 \%$ para todos os sujeitos (entre 72 e $100 \%$ ), exceto na primeira sessão do sujeito L16, em que a porcentagem de acertos para o modelo 'longo' foi $64 \%$.

A Figura 6 apresenta, para cada sujeito, uma função psicométrica, ou seja, a proporção de escolhas de 'longo' em função da duração do modelo nas cinco sessões da fase TRBI+TTBI. Essa medida foi obtida dividindo-se, para cada duração do modelo, o número de escolhas do estímulo de comparação correspondente ao modelo 'longo' pelo número de tentativas em que o modelo foi apresentado. Esses cálculos incluem apenas as 80 tentativas do TTBI em que os estímulos modelos 'curto' e 'longo' foram apresentados juntamente com os modelos de valores intermediários. Assim, a função psicométrica, além de mostrar as escolhas relacionadas aos modelos treinados (pontos extremos), também indica as escolhas relacionadas aos modelos de teste (pontos intermediários). Observa-se que todos os sujeitos tenderam a escolher 'curto' para os modelos de durações menores e, à medida que a duração do modelo aumentou, os sujeitos passaram progressivamente a escolher 'longo', de modo que as curvas tenderam a apresentar um formato sigmoide.

A Figura 6 apresenta também o ponto de igualdade subjetiva (PIS), ou seja, o ponto da função com ordenada igual a 0,5, o qual indica a duração do modelo que o sujeito considerou como 'curto' em metade das tentativas e como 'longo' na outra metade das tentativas. O PIS foi calculado a partir da seguinte equação (Castro \& cols., 2013):

$$
\operatorname{PIS}(X)=\frac{\mathrm{X}_{1}+\left(0,5-\mathrm{Y}_{1}\right) \cdot\left(\mathrm{Y}_{2}-\mathrm{Y}_{1}\right)}{\left(\mathrm{X}_{2}-\mathrm{X}_{1}\right)}
$$

Se for considerada a curva do sujeito L13 como exemplo, a seta indica o valor do PIS $(7,6)$, que na equação é representado pela variável $X$. Os valores de $X_{1}$ e $X_{2}$ correspondem aos pontos na abcissa imediatamente antes e depois do valor do PIS (duração dos modelos 6 e $8 \mathrm{~s}$, respectivamente), e os valores de $\mathrm{Y}_{1}$ e $\mathrm{Y}_{2}$ correspondem aos 
pontos na ordenada imediatamente antes e depois de 0,5 (proporção de longo igual a 0,37 e 0,53, respectivamente). Para animais não humanos, o PIS se aproxima da média geométrica, e para animais humanos, esse ponto tende a se aproximar da média aritmética (Church \& Deluty, 1977). No presente experimento, para os modelos com 2 e 12 s de duração (sujeito L13), a média geométrica é 4,89 s e a média aritmética é 7 s; para os modelos com 2 e $18 \mathrm{~s}$ de duração (demais sujeitos), a média geométrica é $6 \mathrm{~s}$ e a média aritmética é 10 s. Para o sujeito L13, o PIS $(7,6)$ foi mais próximo da média aritmética do que da média geométrica; para os sujeitos L14, L15 e L16, o PIS (5,2; 4,4 e 7,3; respectivamente) se aproximou mais da média geométrica.

\section{Teste de Bissecção}

\section{TRBI+TTBI}

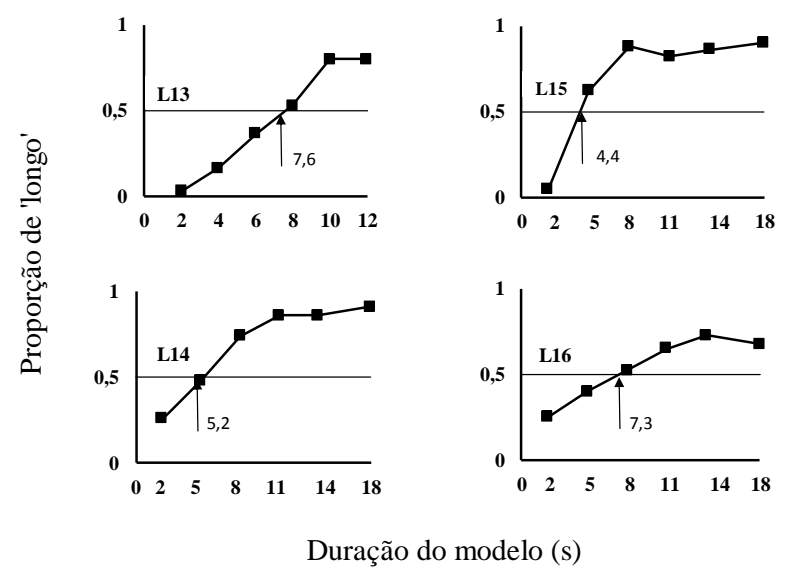

Figura 6. Proporção de escolhas na alternativa 'longo' em função da duração dos modelos apresentados nas cinco últimas sessões da fase TRBI+TTBI. Setas indicam o valor do PIS para cada sujeito no Experimento 2.

Em resumo, as análises da porcentagem de acertos (acima de 80\%) e da proporção de escolhas de 'longo' (mais frequentes com estímulos mais longos), apresentadas nas figuras 5 e 6 , respectivamente, mostram que o treino de bissecção gerou controle discriminativo pela duração dos modelos, um resultado que replica aqueles encontrados em 
diversos estudos (e.g., Arantes \& Machado, 2011; Baumann \& Odum, 2012; Castro \& Machado, 2012; Fox, Smethells \& Reilly, 2013; Galtress \& Kirpatrick, 2010; Marshall \& cols., 2014). Além disso, para dois sujeitos (L14, L15 e L16), o PIS foi próximo da média geométrica, conforme é comumente relatado na literatura (e.g., Church \& Deluty, 1977; Killeen \& Fetterman, 1988; Oliveira \& Machado, 2008; Platt \& Davis, 1983).

A escolha relativa de AC nas 10 sessões da fase TT, expressa como uma proporção da média da escolha relativa de AC das seis últimas sessões da fase LB, é apresentada na Figura 7. Para dois sujeitos (L13 e L14), houve aumento na escolha de AC após o treino e teste de bissecção. Para os outros dois sujeitos (L15 e L16), as escolhas de AC não se alteraram ou diminuíram em algumas sessões. Esses resultados corroboram, parcialmente, os relatos de Baumann e Odum (2012) e Marshall e cols. (2014), os quais apontam que o grau de discriminação temporal se correlaciona positivamente com as escolhas de AC.

\section{Teste IP-AC}

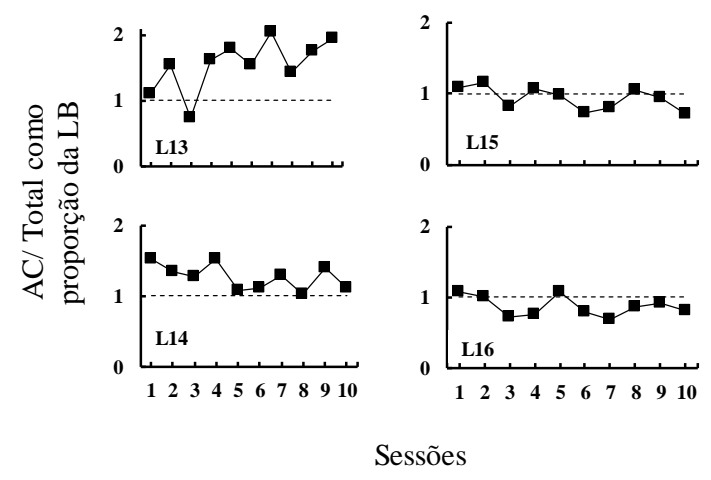

Figura 7. Escolha relativa de AC nas 10 sessões da fase TT como uma proporção da escolha relativa de AC na fase LB, para cada sujeito no Experimento 2.

Os sujeitos que apresentaram aumento nas escolhas por AC também foram aqueles que aprenderam mais rapidamente a discriminação temporal durante o TRBI. Para esses sujeitos, o critério de aprendizagem foi atendido em apenas 10 sessões, enquanto para os sujeitos que não mostraram aumento na escolha por $\mathrm{AC}$, o critério foi atendido em 
aproximadamente 30 sessões (dados não mostrados). A possibilidade de correlação negativa entre escolha de AC e duração do treino de discriminação é apoiada por estudos que mostram que sujeitos que emitem comportamentos impulsivos também apresentam mais erros em tarefas de discriminação temporal (e.g., Barratt, 1983; Baumann \& Odum, 2012; Darcheville \& cols., 2002; Marshall \& cols., 2014; McClure, \& cols., 2014; Van Den Broek \& cols., 1991). Esse ponto será elaborado na Discussão Geral.

\section{EXPERIMENTO 3}

No Experimento 2, durante o qual o treino de bissecção foi realizado em uma fase distinta daquela do teste de escolha IP-AC, houve aumento na escolha relativa de AC para apenas dois de quatro sujeitos. Com o objetivo de promover a obtenção de resultados mais consistentes, no Experimento 3, o treino de bissecção e o teste de escolha IP-AC foram realizados em uma mesma sessão.

\section{Método}

\section{Sujeitos}

Foram utilizados os mesmos sujeitos do Experimento 2.

\section{Equipamento}

Idêntico àquele do Experimento 2.

\section{Procedimento}

O experimento foi composto por duas fases: (1) Linha de Base IP-AC e (2) Treino de Bissecção + Teste IP-AC.

Linha de Base IP-AC (LB). Idêntico à LB do Experimento 1, inclusive para o sujeito L13, pois suas escolhas atingiram a estabilidade com o valor do atraso de AC de 18 s e BO de IP de 33 s. 
Treino de Bissecção (TRBI) + Teste IP-AC (TT). Cada sessão dessa fase era composta por duas partes. A primeira parte correspondia ao procedimento de escolha de acordo com o modelo, conforme descrito na fase TRBI do Experimento 2, com duas diferenças: (1) em vez de 90, havia apenas 40 tentativas (20 com o modelo 'curto' e 20 com o modelo 'longo'); e (2) não havia critério de estabilidade relacionado à porcentagem de acerto. A segunda parte compreendia tentativas de escolha entre IP e AC idênticas àquelas da fase TR+TT do Experimento 1. Essa fase ficou em vigor por 10 sessões.

\section{Resultados e Discussão}

A Figura 8 mostra, para cada sujeito, a escolha relativa de $\mathrm{AC}$ nas seis últimas sessões da fase LB. Assim como na fase LB dos experimentos 1 e 2, todos os sujeitos apresentaram escolhas por AC iguais ou inferiores a 0,40 em todas as sessões, como exigido pelo critério de estabilidade.

\section{Linha de Base IP-AC}

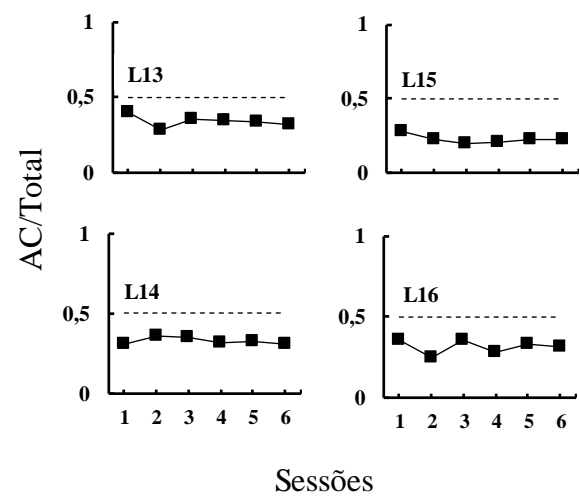

Figura 8. Escolha relativa de AC na seis últimas sessões da fase LB, para cada sujeito no Experimento 3.

A Figura 9 apresenta a porcentagem de acertos para os modelos 'curto' e 'longo' na fase TRBI+TT. Devido a um erro de programação, a porcentagem de acerto não foi 
calculada nas três primeiras sessões do sujeito L13, na primeira e na última sessão dos sujeitos L14 e L15 e nas quatro primeiras sessões do sujeito L16.

\section{Treino de Bissecção}

TRBI+TT
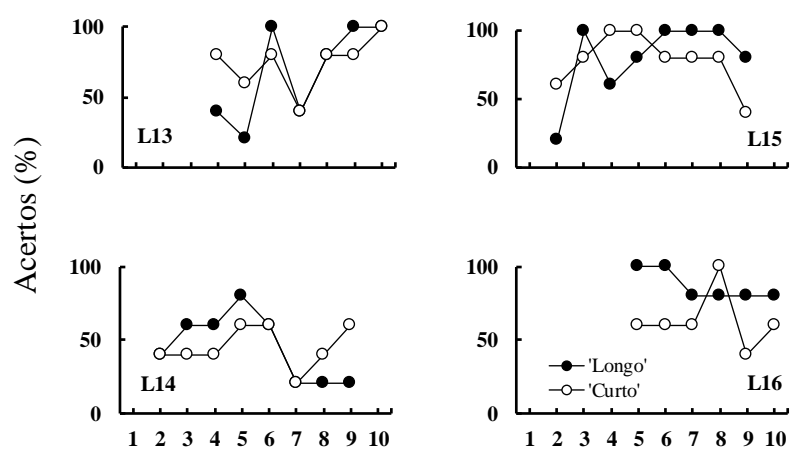

Sessões

Figura 9. Porcentagem de acertos para os modelos 'curto' e 'longo' nas últimas sessões do TRBI para cada sujeito no Experimento 3. Círculos vazios representam o modelo 'curto' e círculos cheios representam o modelo 'longo'.

A porcentagem de acertos variou entre sujeitos e entre sessões, de modo que, na maioria das sessões, essa porcentagem foi menor para os sujeitos L13 e L14 do que para os sujeitos L15 e L16, principalmente com relação ao modelo longo. Além disso, no decorrer dessa fase, os valores obtidos foram menores do que aqueles observados no Experimento 2, principalmente para os sujeitos L13 e L14. Isso pode ter ocorrido devido a três diferenças entre os procedimentos dos experimentos 2 e 3: (1) no Experimento 2, o controle discriminativo foi estabelecido na fase TRBI, anterior ao teste de escolha, enquanto no presente experimento, o treino discriminativo e o teste de escolha ocorreram na mesma sessão (fase TRBI+TT); (2) ao contrário do que ocorreu no Experimento 2, no presente experimento não havia critério de aprendizagem durante o treino de discriminação; e (3) no Experimento 2, os sujeitos foram expostos a, no mínimo, 20 sessões de treino de discriminação, e no presente experimento, a apenas 10 sessões. Outros 
estudos também apontam a influência da duração do treino sobre a aprendizagem (ver Baptista \& Assis, 1995; Barros, Baptista \& Assis, 1998; Harrison \& Green, 1990).

A Figura 10 mostra a escolha relativa de AC, na segunda parte (TT) de cada sessão da fase TRBI+TT, expressa como uma proporção da escolha relativa de AC na fase LB, para cada sujeito (essa medida foi calculada como nos experimentos 1 e 2). Como ocorreu no Experimento 2, o treino de bissecção gerou um aumento nas escolhas relativas de AC para dois sujeitos (L15 e L16); para os demais, o treino de bissecção não afetou a escolha ou produziu diminuição na mesma (L13 e L14). Ou seja, os sujeitos que apresentaram uma discriminação mais acurada (ver Figura 9) foram aqueles que também apresentaram aumento na escolha de AC. Esse resultado corrobora aqueles de diversos estudos (e.g., Barrat, 1983; Baumann, \& Odum, 2012; Darcheville \& cols., 1992; Marshall \& cols., 2014; McClure \& cols., 2014; Van Den Broek \& cols., 1991), os quais relatam uma correlação positiva entre a acurácia da discriminação temporal e escolhas de AC. Esse ponto será abordado novamente na Discussão Geral.

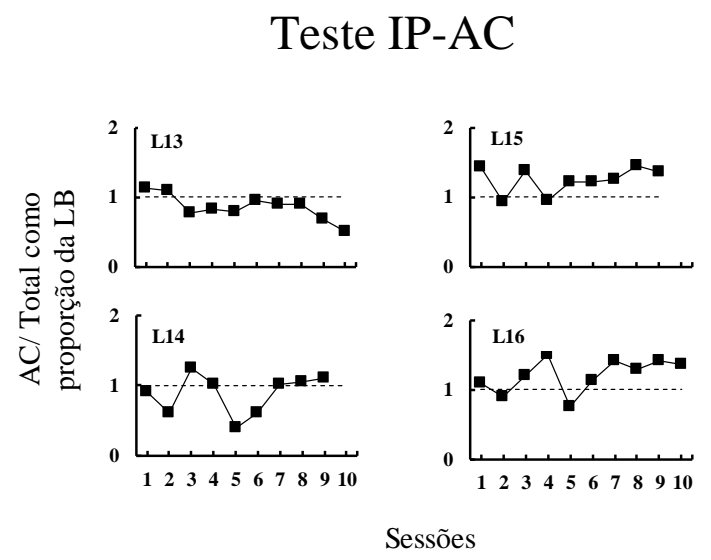

Figura 10. Escolha relativa de AC nas 10 sessões da fase TRBI+TT como uma proporção da escolha relativa de $\mathrm{AC}$ na fase $\mathrm{LB}$, para cada sujeito no Experimento 3 .

Os sujeitos que mostraram aumento nas escolhas de AC no presente experimento foram aqueles que não apresentaram mudanças na escolha de $\mathrm{AC}$ no Experimento 2, 
enquanto que os sujeitos que não mostraram aumentos nas escolhas de $\mathrm{AC}$ no presente experimento foram aqueles que apresentaram aumentos nas escolhas de AC no

experimento anterior. É possível que os aumentos na escolha de AC para os sujeitos L15 e L16 tenham ocorrido em função da segunda exposição ao treino de bissecção. No entanto, os motivos da eliminação do efeito observado, no Experimento 2, para os sujeitos L13 e L14 não foram identificados.

Finalmente, a similaridade entre os resultados dos experimentos 2 e 3 sugere que realizar o TRB e o TT intrassessão, conforme ocorreu no Experimento 3, não promoveu a escolha de AC consistentemente. Talvez isso tenha ocorrido porque o treino de bissecção foi mais curto neste experimento do que no anterior.

\section{DISCUSSÃO GERAL}

O presente estudo expôs ratos a um treino com diferentes esquemas de reforçamento e a um treino de bissecção com o objetivo de verificar se a escolha relativa de AC, avaliada por meio do procedimento de Rachlin (1974), seria afetada. Os resultados do Experimento 1 mostraram que a escolha relativa de AC aumentou, para a maioria dos sujeitos, após o treino com o esquema FR, mas não foi sistematicamente afetada pelos treinos com os esquemas DRL e FI. Os experimentos 2 e 3 mostraram que o treino de bissecção temporal promoveu aumento na escolha relativa de AC para dois sujeitos, enquanto que para outros sujeitos a escolha se manteve constante.

\section{Treino com esquemas de reforçamento}

No presente estudo, os valores dos esquemas FR, DRL e FI foram selecionados de modo a gerar algumas similaridades entre esses esquemas. Ou seja, além da apresentação temporalmente regular (ou aproximadamente regular) dos reforços, os IRIs foram 
comparáveis entre os três esquemas, e próximos ao valor do atraso de AC. Havia, no entanto, uma diferença entre os esquemas. No esquema FR, havia uma exigência de respostas durante o IRI; no esquema DRL, a exigência era que o sujeito não respondesse durante o IRI; e no esquema FI, o responder durante o IRI não era exigido, mas era permitido (nos dois últimos esquemas, apenas uma resposta era exigida ao final do IRI). A análise da pausa pós-reforço durante o esquema FI mostra que os sujeitos emitiram pausas longas e, às vezes, até maiores do que o valor do FI, isto é, apresentaram um responder mais próximo daquele gerado pelo esquema DRL do que pelo esquema FR. A similaridade entre os desempenhos gerados pelos esquemas DRL e FI (taxas de respostas mais baixas), os quais diferiram do desempenho sob o esquema FR (taxas de respostas mais altas), sugerem que o aumento na escolha relativa de AC, observada após o treino com o esquema FR, mas não após o treino com os esquemas DRL e FI, pode ter sido ocasionada pela exigência de respostas durante o IRI. Essa possibilidade é consistente com alguns achados da literatura, os quais indicam que atividades durante o atraso de AC produzem aumento na escolha dessa alternativa (e.g., Darcheville \& cols.,1992; Grosh \& Neuringer, 1981; Mischel \& cols., 1972; Moreira \& Abreu-Rodrigues, 2008).

Segundo Galtress e cols. (2012), Grosh e Neuringer (1981), Marshall e cols. (2014), Mischel e cols. (1972) e Sonunga-Barke e cols. (1992), uma vez que os sujeitos tendem a realizar escolhas que diminuem o tempo de espera para a obtenção do reforço, é possível que o atraso do reforço tenha propriedades aversivas. Adicionalmente, Grosh e Neuringer e Mischel e cols. sugerem que atividades durante o atraso podem reduzir o controle aversivo exercido pelo tempo de espera do reforço e, consequentemente, favorecer as escolhas de AC. Embora, no presente estudo, não houvesse exigência de atividades durante o atraso de AC, e mesmo que a exposição ao esquema FR não tenha alterado o número de respostas emitidas durante esse atraso (dados não mostrados), o responder durante os IRIs do 
esquema FR pode ter exercido o papel de estímulo alterador da função (do inglês function altering stimulus - FAS) da passagem do tempo. De acordo com Schlinger (1993) e Schlinger e Blakely (1987), um FAS é um estímulo que altera a função de outros estímulos. Por exemplo, suponha que uma pessoa nunca fecha as janelas de sua casa ao anoitecer. No entanto, quando alguém the diz "feche as janelas ao anoitecer para evitar mosquitos", o estímulo 'anoitecer' pode ter sua função modificada, de estímulo neutro (antes esse estímulo não evocava a resposta de 'fechar as janelas') para estímulo discriminativo (assim que está presente, esse estímulo passa a evocar a resposta de 'fechar as janelas'). No presente estudo, na primeira exposição ao procedimento de Rachlin, os animais escolheram, preferencialmente, a alternativa de IP, apesar de a magnitude do reforço ser maior na alternativa de AC. Isso sugere que o tempo de espera do reforço apresentava propriedades aversivas. É possível que, durante a exposição ao esquema FR, o responder durante o IRI tenha minimizado, ou mesmo eliminado, a função aversiva do tempo de espera do reforço, e assim, ao ser novamente exposto ao procedimento de Rachlin, essa menor aversividade do atraso tenha permitido uma maior sensibilidade à magnitude do reforço. Consequentemente, as escolhas relativas de AC aumentaram.

A ausência de efeitos sistemáticos dos esquemas DRL e FI não elimina a possibilidade que a exposição a esquemas que geram controle temporal afetem a escolha, como foi indicado por Smith e cols. (2015). Nesse estudo, o único, segundo os autores, que mostra aumento na escolha de AC ao promover uma intervenção baseada no controle temporal, o treino com os esquemas DRL (Experimento 1) e FI (Experimento 2) promoveu a escolha de AC. É possível que a inconsistência entre os resultados obtidos no presente estudo e no de Smith e cols. tenha sido gerada por diferenças entre procedimentos. No estudo de Smith e cols., as sessões compreendiam 180 tentativas, os esquemas concorrentes dos elos iniciais foram programados independentemente, não havia BO após 
o reforço, os atrasos e as magnitudes do reforço foram $10 \mathrm{~s}$ e 1 pelota, respectivamente, no elo terminal IP, e 30 s e 2 pelotas, respectivamente, no elo terminal AC. Além disso, os resultados se baseiam em dados médios de 24 ratos. Finalmente, e talvez mais relevante caso sejam considerados os estudos de discriminação da magnitude do reforço (Marshall \& Kirkpatrick, 2016, Experimento 2; Renda \& Madden, 2016), no estudo de Smith e cols., durante o treino com os esquemas DRL e FI, os sujeitos foram expostos a dois valores diferentes de cada esquema, um referente ao atraso de IP e outro referente ao atraso de AC, nas barras correlacionadas com os elos terminais de IP e AC, respectivamente, enquanto no presente estudo, os animais foram expostos a apenas um valor do esquema (aquele correspondente ao atraso de AC). Diante disso, é possível que, para promover a escolha de AC, talvez seja necessário não apenas desenvolver controle por uma unidade de tempo (ou mais especificamente, regulação temporal), mas a discriminação de diferentes unidades de tempo, um aspecto que será discutido a seguir.

\section{Treino de bissecção}

Nos experimentos 2 e 3 foi utilizado o procedimento de bisseção. Os procedimentos dos dois experimentos diferiram à medida que, no Experimento 3, o treino de bisseção envolveu a apresentação de apenas $11 \%$ do número de tentativas que foram apresentadas no Experimento 2, não havia critério de aprendizagem durante o treino bissecção e não havia teste de bisseção. Além disso, no Experimento 3, o treino de bissecção foi apresentado na mesma sessão do teste de escolha entre IP e AC. Em ambos os experimentos, todos os sujeitos apresentaram controle discriminativo pela duração dos modelos, como é comumente encontrado na literatura (e.g., Arantes \& Machado, 2011; Castro \& Machado, 2012; Church \& Deluty, 1977; Fox \& cols., 2013; Galtress \& Kirpatrick, 2010; Oliveira \& Machado, 2008; Platt \& Davis, 1983), mas o aumento na 
escolha relativa de AC, relatado por alguns autores (e.g., Baumann \& Odum, 2012; Marshall \& cols., 2014), foi observado para apenas dois sujeitos em cada experimento.

Os achados sugeriram uma correlação entre a duração (ou erros) do treino de bissecção e a escolha de AC, pois os sujeitos que atingiram o critério de estabilidade mais rapidamente (ou, em se tratando do Experimento 3, apresentaram maior porcentagem de acertos, principalmente para o estímulo 'longo') no treino de bissecção também foram aqueles que apresentaram aumento na escolha relativa de AC. Alguns autores (e.g., Baumann \& Odum, 2012; Takahashi, 2005; Wittmann \& Paulus, 2008) sugerem que erros em tarefas de discriminação temporal ocorrem porque os sujeitos tendem a superestimar o intervalo de tempo, ou seja, tendem a mostrar imprecisão temporal, e que tal imprecisão se correlaciona com escolhas impulsivas. Diante dessas considerações, é viável supor que o treino realizado nos experimentos 2 e 3 , embora tenha promovido a discriminação entre os valores dos atrasos de IP e AC, não reduziu, necessariamente, a imprecisão temporal. Isto é, os sujeitos aprenderam que um modelo era longo e que o outro era curto, mas não, necessariamente, o quão longo ou o quão curto era cada modelo. Assim, é possível que aumentos na escolha de AC tenham ocorrido apenas quando a imprecisão temporal foi reduzida; quando essa imprecisão se manteve, apesar da discriminação entre as durações dos modelos, a escolha de AC permaneceu inalterada. Essa sugestão se apoia nos resultados de Smith e cols. (2015, Experimento 2), os quais observaram uma correlação positiva entre precisão temporal, avaliada por meio do procedimento de pico, e escolha de AC.

Uma questão permanece. Por que os sujeitos L13 e L14 que, no Experimento 2, aprenderam mais rapidamente a tarefa de discriminação temporal e mostraram um aumento na escolha de AC, não mostraram um resultado similar no Experimento 3? Ou seja, por que esses sujeitos apresentaram uma discriminação menos acurada e escolhas de AC 
inalteradas no Experimento 3? Como assinalado anteriormente, no Experimento 3, o treino de bissecção e a tarefa de escolha entre IP-AC foram realizados em uma mesma sessão, não havia critério de aprendizagem no treino e os sujeitos também não foram expostos ao teste de bisseção, fatores que podem ter contribuído para os resultados obtidos. No entanto, esses fatores estiveram presentes para os quatro sujeitos, mas apenas dois deles apresentaram uma 'piora' no desempenho.

\section{Considerações finais}

Os resultados aqui obtidos apontam algumas variáveis de controle em situações de escolha entre IP e AC. Primeiro, o aumento na escolha de AC após a exposição ao esquema FR, mas não após a exposição aos esquemas DRL e FI, sugere que a exigência de respostas durante o IRI é uma variável relevante (Experimento 1 do presente estudo; ver também Darcheville \& cols., 1992; Grosh \& Neuringer, 1981; Mischel \& cols., 1972; Moreira \& Abreu-Rodrigues, 2008). Segundo, a ausência de efeito dos treinos DRL e FI, ambos com apenas uma unidade temporal (Experimento 1 do presente estudo), aliada ao fato de que aumentos nas escolhas de AC podem ocorrer quando há um treino discriminativo entre duas unidades temporais (e.g., experimentos 2 e 3 do presente estudo; ver também Barratt, 1983; Baumann \& Odum, 2012; Darcheville \& cols., 1992; Marshall \& cols., 2014; McClure \& cols., 2014; Van Den Broek \& cols., 1991), sugere que a discriminação temporal é uma variável de controle adicional. Finalmente, o grau de precisão temporal também deve ser considerado, uma vez que discriminação temporal nem sempre favorece as escolhas de AC (experimentos 2 e 3 do presente estudo) e já que uma correlação positiva entre precisão temporal e escolha de AC já foi relatada (e.g. Smith \& cols., 2015). 
Finalmente, algumas modificações no procedimento poderiam contribuir para a caracterização da relação entre controle temporal e autocontrole. As duas variáveis de interesse no presente trabalho - exigência ou não de atividade durante o IRI e a discriminação de intervalos com durações diferentes - poderiam ser investigadas por meio de um treino com três esquemas múltiplos, cada um com dois componentes: mult FR FR, mult DRL DRL e mult FI FI. Os componentes de cada esquema se diferenciariam em termos do tamanho do IRI: em um componente, o IRI seria similar ao atraso de AC, e no outro, ao atraso de IP. Uma vez que em cada esquema múltiplo estaria em vigor um esquema de reforçamento diferente (FR, DRL e FI), e já que os componentes de cada esquema múltiplo teriam IRIs distintos, os efeitos da exigência ou não de respostas e da discriminação temporal sobre as escolhas de AC seriam identificados. Além disso, o procedimento poderia incluir algumas tentativas de pico, de modo a permitir a avaliação do papel da precisão temporal.

\section{Referências}

Ainslie, G. (1975). Specious reward: A behavioral theory of impulsiveness and impulse control. Psychology Bulletin, 82, 493-496.

Alling, K., \& Poling, A. (1995). The effects of differing response-force requirements on fixed-ratio response of rats. Journal of the Experimental Analysis of Behavior, 63, 331-346.

Arantes, J., \& Machado, A. (2011). Errorless learning of a conditional temporal discrimination. Journal of the Experimental Analysis of Behavior, 95, 1-20.

Baptista, M.Q.G. \& Assis, G.J.A. (1995). Treino por consistência de estímulos sem consequências diferenciais. Psicologia: Teoria e Pesquisa, 11, 173-179. 
Barbosa, A. S. (2010). Tomada de decisão e desvalorização pelo atraso de estímulos apetitivos e aversivos em fumantes (Dissertação de Mestrado). Retirado do repositório digital da Universidade Federal do Rio Grande do Sul.

Barratt E. S. (1983). The biological basis of impulsiveness: The significance of timing and rhythm disorders. Personality and Individual Differences, 4, 387391.

Barros, C.W.L., Baptista, M.Q.G. \& Assis, G.J.A. (1998). Efeitos de história de treino sobre a formação de classes de estímulos equivalentes. Acta Comportamentalia, 6, 111-128.

Baumann, A. A., \& Odum, A. L. (2012). Impulsivity, risk taking and timing. Behavior Processes, 90, 408-414.

Beeby, E., \& White, G. (2013). Preference reversal between impulsive and self-control choice. Journal of the Experimental Analysis of Behavior, 99, 260-276.

Catania, A. C. (1991). Time as a variable in behavior analysis. Em H. Iversen \& K. A. Lattal (Eds.), Experimental analysis of behavior (Vol. 2, pp. 1-120). New York: Elsevier.

Catania, A. C. (1999). Aprendizagem: comportamento, linguagem e cognição (D. G. Souza, Trad.). Porto Alegre: Artmed (Obra originalmente publicada em 1998).

Castro, A. C. V., \& Machado, A. (2012). The interaction of temporal generalization gradients predicts the context effect. Journal of the Experimental Analysis of Behavior, 97, 263-279.

Castro, A. C. V., Carvalho, M. P., Kroger-Costa, A., \& Machado, A. (2013). A percepção do tempo: contributos do procedimento de bissecção. Temas em Psicologia, 21, 4970.

Chung, S. (1965). Effects of effort on response rate. Journal of the Experimental Analysis of Behavior, 8, 1-7. 
Church, R. M., \& Deluty, M. Z. (1977). Bisection of temporal intervals. Journal of Experimental Psychology: Animal Behavior Processes, 3, 216-228.

Coelho, C., Hanna, E. S., \& Todorov, J. C. (2003). Magnitude, atraso e probabilidade de reforço em situações hipotéticas de risco. Psicologia: Teoria e Pesquisa, 19, 269-278.

Cole, M. R. (2011). The long term-effect of high-and-low-rate responding histories on fixed-interval responding in rats. Journal of the Experimental Analysis of Behavior, $75,43-54$.

Darcheville, J. C., Riviere, V., \& Wearden, J. H. (1992). Fixed-interval performance and self-control in children. Journal of the Experimental Analysis of Behavior, 57, 187199.

Dukich, T. D., \& Lee, A. E. (1973). A comparison of measures of responding under fixedinterval schedules. Journal of the Experimental Analysis of Behavior, 20, 281-290.

Eisenberger, R., \& Adornetto, M. (1986). Generalized self-control of delay and effort. Journal of Personality and Social Psychology, 51, 1020-1031.

Ferster, C. B., \& Skinner, B. F. (1957). Schedules of reinforcement. New York: AppletonCentury- Crofts.

Flora, S. R., \& Pavlik, W. B. (1992). Human self-control and the density of reinforcement. Journal of the Experimental Analysis of Behavior, 57, 201-208.

Fox, A. T., Smethells, J. R., \& Reilly, M. P. (2013). Flash rate discrimination in rats: Bisection and generalization peak shift. Journal of the Experimental Analysis of Behavior, 100, 211-221.

Galtress, T., Garcia, A., \& Kirkpatrick, K. (2012). Individual differences in impulsive choice and timing in rats. Journal of the Experimental Analysis of Behavior, 98, 6587. 
Galtress, T., \& Kirkpatrick, K. (2010). Reward magnitude effects on temporal discrimination. Learning and Motivation, 41, 108-124.

Green, L., \& Estle, S. J. (2003). Preference reversals with food and water reinforces in rats. Journal of the Experimental Analysis of Behavior, 79, 233-242.

Green, L., \& Synderman, M. (1980). Choice between rewards differing in amount and delay: Toward a choice model of self control. Journal of the Experimental Analysis of Behavior, 34, 135-147.

Green, L., Fisher E. B, Jr., Perlow S., \& Sherman L. (1981). Preference reversal and selfcontrol: Choice as a function of reward amount and delay. Behavior Analysis Letters, 1, 43-51.

Grosh, J., \& Neuringer, A. (1981). Self-control in pigeons under the Mischel paradigm. Journal of the Experimental Analysis of Behavior, 35, 3-21.

Hackenberg, T. D., \& Vaidya, M. (2003). Determinants of pigeons' choices in token-based self-control procedures. Journal of the Experimental Analysis of Behavior, 70, 207218.

Hanna, E. S., \& Todorov, J. C. (2002). Modelos de autocontrole na análise experimental do comportamento: utilidade e crítica. Psicologia Teoria e Pesquisa, 18, 337343.

Harrison, R. J., \& Green, G. (1990). Development of conditional and equivalence relations without differential consequences. Journal of the Experimental Analysis of Behavior, 54, 225-237.

Harzem, P., Lowe, F. P., \& Spencer, P. T. (1978). Temporal control of behavior: Schedule interactions. Journal of the Experimental Analysis of Behavior, 30, 255-270.

Killeen, P. R., \& Fetterman, J. C. (1988). A behavioral theory of timing. Psychological Review, 95, 274-285. 
LeFrancois, J. R., \& Metzger, B. (1993). Low-response-rate conditioning history and fixed interval responding in rats. Journal of the Experimental Analysis of Behavior, 59, 543-549.

Lima, K, L. B. A. (2011). Taxa de desconto com procedimento de atraso e probabilidade do reforço: efeitos da exposição ao álcool durante a adolescência em ratos (Dissertação de Mestrado). Retirado do repositório institucional da Universidade de Brasília.

Logue, A.W., Peña-Correal, E., Rodrigues, M. L., \& Kabela, E. (1986). Self-control in adult humans: Variation in positive reinforcer amount and delay. Journal of the Experimental Analysis of Behavior, 46, 159-173.

Marshall, A. T., \& Kirkpatrick, K. (2016). Mechanisms of impulsive choice: III. The role of rewards processes. Behavioural Processes, 123, 134-148.

Marshall, A. T., Smith, A. P., \& Kirkpatrick, K. (2014). Mechanisms of impulsive choice: I. Individual differences in interval timing and reward processing. Journal of the Experimental Analysis of Behavior, 102, 86-101.

Mazur, J. E. (1987). An adjusting procedure for studying delayed reinforcement. In M. L. Commons, J. E. Mazur, J. A. Nevin \& H. Rachlin (Eds.), Quantitative analysis of behavior: Vol. 5. The effect of delay and of intervening events on reinforcement value (pp. 55-73). Hillsdale, NJ: Erlbaum.

McClure, J., Podos, J., \& Richardson, H. N. (2014). Isolating the delay component of impulsive choice in adolescent rat. Frontiers in Neuroscience, 8, 1-19.

Miller, L. K. (1970). Some punishing effects of response-force. Journal of the Experimental Analysis of Behavior, 13, 215-220.

Mischel, W., \& Ebbesen, E. B. (1970). Attention in delay of gratification. Journal of Personality and Social Psychology, 16, 329-337. 
Mischel, W., Ebbesen, E. B., \& Zeiss, A. (1972). Cognitive and attentional mechanisms in delay of gratification. Journal of Personality and Social Psychology, 21, 204-218.

Moreira, J. M., \& Abreu-Rodrigues, J. (2008). Atividade durante o atraso: efeitos sobre a escolha de autocontrole e impulsividade. Revista Brasileira de Análise do Comportamento, 4, 53-70.

Navarick, D. J. (1987). Reinforcement probability and delay as determinants of human impulsiveness. The Psychological Record, 37, 219-226.

Navarick, D. J. (1998). Impulse choice in adults: How consistent are individual differences? The Psychological Record, 48, 665-674.

Oliveira, L., \& Machado, A. (2008). The effect of sample duration and cue on a double temporal discrimination. Learning and Motivation, 39, 71-94.

Platt, J. R., \& Davis, E. R. (1983). Bisection of temporal interval by pigeons. Journal of Experimental Psychology: Animal Behavior Processes, 9, 160-170.

Porto, T. H., Ramos, M. N., \& Costa, C. E (2011). História de aquisição do comportamento em um múltiplo FR-DRL: diferenciação e estabilidade das taxas de respostas. Acta Comportamentalia, 19, 281-306.

Renda, C. R., \& Madden, J. G. (2016). Impulsive choice and pre-exposure to delays. III. Four-month test-retest outcomes in male wistar rats. Behavioural Processes, 126, 108-112.

Rachlin, H. (1974). Self-control. Behaviorism, 2, 94-107.

Rachlin, H., Castrogiovanni, A., \& Cross, D. (1987). Probability and delay in commitment. Journal of the Experimental Analysis of Behavior, 48, 347-353.

Rachlin, H., \& Green, L. (1972). Commitment, choice and self-control. Journal of the Experimental Analysis of Behavior, 17, 15-22. 
Rachlin, H., Raniere, A., \& Cross. D. (1991). Subjective probability and delay. Journal of the Experimental Analysis of Behavior, 55, 233-244.

Schlinger, H. D. (1993). Separating discriminative and function-altering effects of verbal stimuli. The Behavior Analyst, 16, 9-23.

Schlinger, H. D., \& Blakely, E. (1987). Function-altering effects of contingency-specifying stimuli. The Behavior Analyst, 10, 41-45.

Schneider, B. A. (1969). A two-state analysis of fixed-interval responding in the pigeon. Journal of the Experimental Analysis of Behavior, 12, 677-687.

Skinner, B. F. (2003). Ciência e comportamento humano (J. C. Todorov, R. Azzi, Trads.). São Paulo: Martins Fontes (Obra originalmente publicada em 1953).

Smith, A. P., Marshall, A. T., \& Kirkpatrick, K. (2015). Mechanisms of impulsive choice: II. Time-based interventions to improve self-control. Behavioural Processes, 112, 24-92.

Snyderman, M. (1983). Delay and amount of reward in a concurrent chain. Journal of the Experimental Analysis of Behavior, 39, 437-447.

Sonunga-Barke, E. J. S, Taylor, E., Sembi, S., \& Smith, J. (1992). Hyperactivity and delay aversion: I. The effect of delay on choice. The Journal of Child Psychology and Psychiatry, 33, 387-398.

Takahashi, T. (2005). Loss of self-control in intertemporal choice may be attributable to logarithmic time-perception. Medical Hypotheses, 65, 691-693.

Van Den Broek, M. D., Bradshaw, C. M., \& Szabadi, E. (1991). Behaviour of 'impulsive' and 'non-impulsive' humans in a temporal differentiation schedule of reinforcement. Personality and Individual Differences, 8, 233-239.

Weiner, H. (1969). Controlling human fixed-interval performance in rats. Journal of the Experimental Analysis of Behavior, 12, 349-373. 
Wittmann, M., \& Paulus, M. P. (2008). Decision making, impulsivity and time perception. Trends in Cognitive Sciences, 12, 7-12.

Yi, R., \& Bickel, W. K. (2005). Representation of odds in terms of frequencies reduces probability discounting. The Psychological Record, 55, 577-593.

Zeiler, M. D., \& Powell, D. G. (1994). Temporal control in fixed-interval schedules. Journal of the Experimental Analysis of Behavior, 61, 1-9. 